\title{
Decellularization Strategies for Regenerating Cardiac and Skeletal Muscle Tissues
}

\author{
Yong How $\operatorname{Tan}^{\dagger}$, Haylie R. Helms ${ }^{\dagger}$ and Karina H. Nakayama* \\ Department of Biomedical Engineering, Oregon Health and Science University, Portland, OR, United States
}

OPEN ACCESS

Edited by:

Laura lop,

University of Padua, Italy

Reviewed by:

Jangwook $P$. Jung,

Louisiana State University,

United States

Akio Kishida,

Tokyo Medical and Dental University,

Japan

*Correspondence:

Karina H. Nakayama

Nakayaka@ohsu.edu

${ }^{\dagger}$ These authors have contributed equally to this work

Specialty section:

This article was submitted to Biomaterials,

a section of the journal

Frontiers in Bioengineering and

Biotechnology

Received: 08 December 2021

Accepted: 28 January 2022

Published: 28 February 2022

Citation:

Tan YH, Helms HR and Nakayama KH (2022) Decellularization Strategies for

Regenerating Cardiac and Skeletal

Muscle Tissues.

Front. Bioeng. Biotechnol. 10:831300.

doi: $10.3389 /$ fbioe.2022.831300
Cardiovascular disease is the leading cause of death worldwide and is associated with approximately 17.9 million deaths each year. Musculoskeletal conditions affect more than 1.71 billion people globally and are the leading cause of disability. These two areas represent a massive global health burden that is perpetuated by a lack of functionally restorative treatment options. The fields of regenerative medicine and tissue engineering offer great promise for the development of therapies to repair damaged or diseased tissues. Decellularized tissues and extracellular matrices are cornerstones of regenerative biomaterials and have been used clinically for decades and many have received FDA approval. In this review, we first discuss and compare methods used to produce decellularized tissues and ECMs from cardiac and skeletal muscle. We take a focused look at how different biophysical properties such as spatial topography, extracellular matrix composition, and mechanical characteristics influence cell behavior and function in the context of regenerative medicine. Lastly, we describe emerging research and forecast the future high impact applications of decellularized cardiac and skeletal muscle that will drive novel and effective regenerative therapies.

Keywords: decellularized muscle, decellularized heart, dECM, decellularized extracellular matrix, skeletal muscle engineering, cardiac engineered tissue, ECM, extracellular matrix

\section{INTRODUCTION}

Cardiovascular disease and musculoskeletal conditions together represent a major global health burden. According to the World Health Organization (WHO), cardiovascular disease is the leading cause of death worldwide and accounts for an estimated 17.9 million deaths annually (World Health Organization, 2021a). Separately, an astonishing 1.71 billion global citizens are affected by musculoskeletal conditions and is the leading cause of disability in 160 countries (World Health Organization, 2021b). Combined, these two health crises are responsible for a global annual economic burden of approximately $\$ 1.8$ trillion (Bloom et al., 2011; Yelin et al., 2021). These statistics are projected to only worsen by 2030 unless a major shift in treatment options becomes widely available. Regenerative medicine reconceptualizes the approach to this challenge with technologies that potentiate cures over treatments. Through the modulation of the body's response to injury and disease using bioactive materials, the potential for full restoration of function is on the horizon.

Decellularized tissues and extracellular matrices (ECM) are the heavyweights of regenerative biomaterials with decades of clinical use and FDA approvals. These materials possess potent regenerative properties and have the potential to repair and restore function to a wide range of injured and diseased tissues including cardiac and skeletal muscle. In this review, the application of 


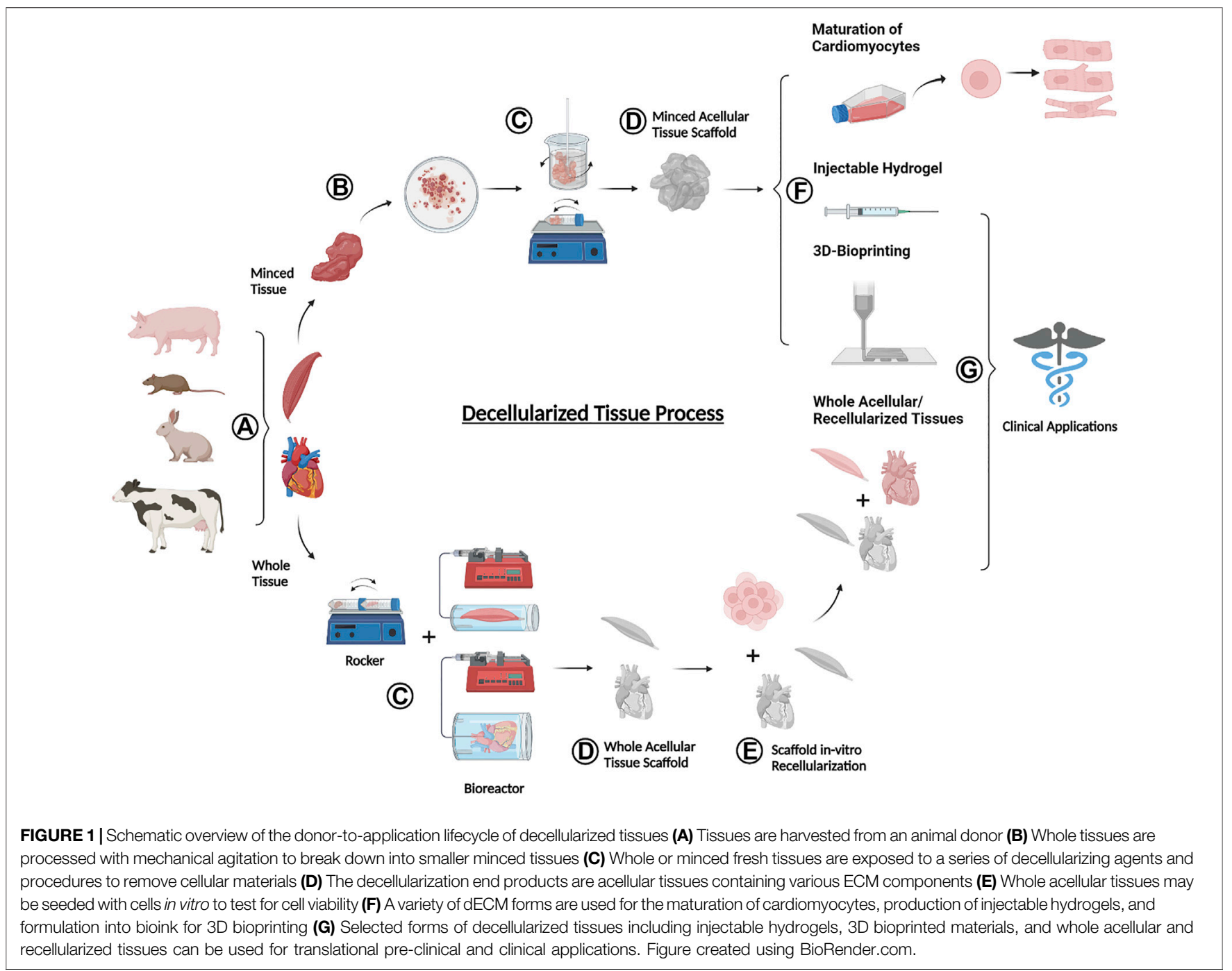

decellularized ECM (dECM) in the cellular modulation and regeneration of cardiac and skeletal muscle is described. Specifically, the most widely used decellularization protocols for generating dECM from these two tissues are compared. Herein, we describe how the biophysical properties of composition, topographical and spatial patterning, and biomechanical force transduction are impacted by the decellularization protocol as well as characterize the modulatory role that these properties play in guiding cellular and host interactions in vitro and in vivo.

\section{METHODS OF DECELLULARIZATION}

The global process of decellularization involves a series of steps that take the tissue from donor to regenerative application (Figure 1). This is done by harvesting tissues from a donor animal (Figure 1A), followed by the application of a series of reagent and wash solutions that lyse cells and remove nuclear materials (Figure 1B,C) to leave behind a structural matrix made up of ECM proteins (Figure 1D). The resulting dECM can then be used as a cell culture tool, solubilized into bioink for $3 \mathrm{D}$ printing, or cultured with cells to be transplanted as a regenerative therapeutic into an animal injury model (Figure 1E-G).

Historically, tissues have been decellularized primarily via three methods that are based in chemical, physical, and/or enzymatic disruption of the cell-matrix interface. Chemical decellularization utilizes detergents, alcohols, or $\mathrm{pH}$ changes to lyse cells by disrupting the cell membrane (Gilpin and Yang, 2017; KC et al., 2019). Methods of physical decellularization include freeze-thaw cycles, agitation, mechanical manipulation, or pressure to forcibly remove cells (Gilpin and Yang, 2017; KC et al., 2019). Lastly, enzymatic decellularization breaks down the protein interactions through the use of nucleases, collagenases, and proteases and/or chelating agents such as ethylenediamine tetraacetic acid (EDTA) or ethylene glycol tetraacetic acid (EGTA) (Gilpin and Yang, 2017; KC et al., 2019). Along with each decellularization approach are associated advantages and disadvantages which must be carefully considered for the end application. 
TABLE 1 | Cardiac decellularization protocols.

\begin{tabular}{|c|c|c|c|c|c|}
\hline Application & Species & $\begin{array}{l}\text { Tissue } \\
\text { form }\end{array}$ & $\begin{array}{l}\text { Decellularization } \\
\text { treatments }\end{array}$ & Study findings & Citation \\
\hline Decell Methods & Porcine & Whole & Inversion $+45^{\circ} ; \mathrm{NaCl} ;$ SDS & $\begin{array}{l}\text { Improved perfusion efficiency; better DNA clearance, retention } \\
\text { of ECM and heart shape }\end{array}$ & Lee et al. (2017) \\
\hline Decell Methods & Porcine & Whole & Freeze/thaw; SDC; Triton; PAA & $\begin{array}{l}\text { Extensive decellularization while retaining architecture and } \\
\text { angiogenic growth factors }\end{array}$ & Methe et al. (2014) \\
\hline Decell Methods & Porcine & Whole & $\begin{array}{l}\text { 1. Freeze/thaw; Trypsin } \\
\text { 2. Freeze/thaw; Triton }\end{array}$ & $\begin{array}{l}\text { Multiphoton microscopy and image correlation spectroscopy } \\
\text { can predict mechanical properties of dECM }\end{array}$ & Merna et al. (2013) \\
\hline Decell Methods & Rat & Whole & $\begin{array}{l}\text { Freeze/thaw; Trypsin; SDS; } \\
\text { Triton; DCA; PAA + EtOH }\end{array}$ & $\begin{array}{l}\text { Little residual nuclear material; minimizes damage to proteins; } \\
\text { retention of heart shape }\end{array}$ & Ozlu et al., 2019 \\
\hline $\begin{array}{l}\text { Decell/Recell } \\
\text { Methods }\end{array}$ & Porcine & Whole & $\begin{array}{l}\text { Freeze/thaw; Trypsin; Triton; } \\
\text { DCA; PAA + EtOH }\end{array}$ & $\begin{array}{l}\text { Significantly reduced decellularization time to } 10 \mathrm{~h} \text { without } \\
\text { damaging the ECM }\end{array}$ & Wainwright et al. (2010) \\
\hline $\begin{array}{l}\text { Decell/Recell } \\
\text { Methods }\end{array}$ & Rat & Whole & SDS; Triton & $\begin{array}{l}\text { Preserved ECM characteristics; promoted hESC-CM } \\
\text { attachment, maturation, and electrical activity }\end{array}$ & $\begin{array}{l}\text { Hochman-Mendez et al. } \\
\text { (2020) }\end{array}$ \\
\hline $\begin{array}{l}\text { Decell/Recell } \\
\text { Methods }\end{array}$ & Rat & Whole & Heparin, Adenosine; SDS; Triton & $\begin{array}{l}\text { ECM preserved and vasculature perfusable; cardiac and EC } \\
\text { recellularization; stimulation produced myocardial contractions }\end{array}$ & Ott et al. (2008) \\
\hline $\begin{array}{l}\text { Decell/Recell } \\
\text { Methods }\end{array}$ & Mouse & Whole & $\begin{array}{l}\text { Freeze/thaw; Trypsin; SDS; } \\
\text { Triton; DCA; PAA + EtOH }\end{array}$ & $\begin{array}{l}\text { Cardiac progenitors grown on dECM migrate, proliferate, and } \\
\text { differentiate into } \mathrm{CMs}, \mathrm{SMC} \text {, and ECs }\end{array}$ & Lu et al. (2013) \\
\hline Recell Methods & Rat & Whole & SDS; Triton & Reendothelialization best with both venous and arterial delivery & Robertson et al. (2014) \\
\hline $\begin{array}{l}\text { Cell Culture } \\
\text { Additive }\end{array}$ & Human & Minced & $\mathrm{NaCl} ; \mathrm{SDS}$ & $\begin{array}{l}\text { Atrial dECM in hiPSC-CM differentiation drives atrial } \\
\text { cardiomyocyte subtype specification }\end{array}$ & Mesquita et al. (2021) \\
\hline $\begin{array}{l}\text { Cell Culture } \\
\text { Additive }\end{array}$ & Porcine & Minced & SDS; Triton & $\begin{array}{l}\text { Fetal ECM increased neonatal CM attachment and proliferation } \\
\text { compared to PLL, adult ECM, or neonatal ECM }\end{array}$ & Williams et al. (2014) \\
\hline $\begin{array}{l}\text { Cell Culture } \\
\text { Additive }\end{array}$ & Bovine & Minced & Freeze/thaw; SDS; Triton & $\begin{array}{l}\text { 3D ECM enhances iPSC-CM maturation compared to 2D } \\
\text { culture }\end{array}$ & Fong et al. (2016) \\
\hline $\begin{array}{l}\text { Injectable } \\
\text { Therapeutic }\end{array}$ & Porcine & Minced & SDS; Triton & $\begin{array}{l}\text { Injection of solubilized fetal ECM decreased fibrosis and } \\
\text { improved cardiac function post Ml }\end{array}$ & Wang, X. et al., 2020 \\
\hline $\begin{array}{l}\text { Injectable } \\
\text { Therapeutic }\end{array}$ & Mouse & Minced & $\begin{array}{l}\text { Freeze/thaw; RBC lysis; DNase I } \\
\text { + RNase }\end{array}$ & $\begin{array}{l}\text { Neonatal ECM decreased fibrosis, promoted angiogenesis, } \\
\text { and increased cardiac function post MI; adult ECM did not } \\
\text { have the same regenerative effects }\end{array}$ & Wang, Z. et al., 2019 \\
\hline Hydrogel & Porcine & Minced & SDS; Triton; PAA + EtOH & $\begin{array}{l}\text { Developed a hydrogel with tunable mechanical and electrical } \\
\text { properties; hydrogel improved hiPSC-CM maturation }\end{array}$ & Tsui et al. (2021) \\
\hline Hydrogel & Bovine & Minced & SDS; Triton & Developed an electroactive, in situ forming, ECM hydrogel & Mousavi et al. (2021) \\
\hline Hydrogel/Bioink & Human & Minced & Freeze/Thaw; SDS; Triton & $\begin{array}{l}\text { GelMA-MeHA-ECM bioink improved mechanical properties; } \\
\text { created an in vitro } \mathrm{Ml} \text { model with the bioink }\end{array}$ & Basara et al. (2021) \\
\hline Hydrogel/Bioink & Porcine & Minced & SDS & $\begin{array}{l}\text { Human cardiac progenitor cells in GelMA-ECM bioink had } \\
>75 \% \text { viability and increased cardiogenic gene expression }\end{array}$ & Bejleri et al. (2018) \\
\hline
\end{tabular}

Modern decellularization strategies often involve a balance between effective and efficient removal of cellular debris with the loss of key proteins and matrix components. For example, sodium dodecyl sulfate (SDS) is a chemical decellularization agent that is highly effective in lysing cells but can alter the microstructure of ECM and is cytotoxic if not thoroughly removed (Gilpin and Yang, 2017). Another widely used detergent, Triton X-100, generally preserves the ECM composition and biomechanics but is less effective in the complete clearing of nuclear material (Ott et al., 2008; Merna et al., 2013; Gilpin and Yang, 2017). Similarly, physical decellularization has a high retention and structural preservation of ECM proteins and mechanical properties but is more likely to leave remnant DNA or DNA fragments behind (Gilpin and Yang, 2017). Enzymatic decellularization involves potent digestive enzymes that are efficient at breaking down and removing cellular debris but has been found to decrease glycosaminoglycan (GAG) content and degrade crosslinking proteins leading to altered mechanical properties (Gilpin and Yang, 2017). There is no universal reagent or protocol, but instead the selection of the most appropriate decellularization approach heavily depends on the final application and will dictate the hierarchy of properties to retain. The choice is further complicated by the compositional variations between tissue types, specifically differences in anatomical structure, function, and age. In this section we discuss the range of methods used to decellularize two kinds of muscle tissues, cardiac muscle and skeletal muscle.

\subsection{Decellularization Methods for Cardiac Tissue}

In 2008, Doris Taylor's group reported the landmark decellularization of a whole heart and simultaneously catapulted an emerging field to the forefront of tissue engineering and regenerative medicine (Ott et al., 2008). Their chemical decellularization approach utilized perfusion of $1 \%$ SDS and $1 \%$ Triton X-100, with deionized water and $1 \mathrm{X}$ PBS washes. This dynamic protocol proved effective in removing native cellular material (residual DNA <4\%) while preserving GAG content and fiber composition. The resulting dECM matrix supported the culture of neonatal cardiac cells, without any noted complications from residual reagents. Other whole heart 
decellularization protocols have built upon the concepts initially established by Ott et al. (Ott et al., 2008) and even this group has since modified their protocol to incorporate osmotic shock and anatomical inversion during decellularization (Lee et al., 2017) (Table 1). Nevertheless, since 2008, this protocol has continued to serve as a foundation for tissue decellularization strategies and a major catalyst for innovation.

Optimization of cardiac decellularization has been guided by the dual goal of ensuring removal of cellular materials and preservation of ECM components. These aims motivated the next generation of decellularization strategies that sought to reduce exposure to harsh reagents through decreased decellularization times. Wainwright et al. was able to significantly reduce total decellularization time to $10 \mathrm{~h}$, compared to the conventional 5-10 days, by using a series of hypertonic, hypotonic, enzymatic, acid, and detergent solutions without damaging the ECM (Wainwright et al., 2010). This time was reduced even further to $2 \mathrm{~h}$ and 15 min using a similar mixed method approach (Lu et al., 2013). However, there is no consensus on which component of a decellularization protocol is most critical and method selection is often based on the desired end application properties. In 2011, Akhyari et al. sought to find the best whole heart decellularization protocol in terms of cellular removal, residual DNA, retention of structural proteins, and biocompatibility (Akhyari et al., 2011). Following a comprehensive comparison of four different methods, using a fully automated system, it was concluded that no single approach was superior to the others. While some protocols were more effective at removal of cellular materials, others better preserved the native dECM proteins. Each protocol had a compromise of strengths and limitations and serves as another example to underscore the need to carefully select the appropriate decellularization method based on the final desired ECM properties.

In recent years, the cardiac field has seen a pivot away from using whole tissue matrices for tissue engineered and regenerative therapeutics towards AECM that is ground or solubilized with primary focus on answering in vitro biological questions. For these applications, the native heart tissue is minced, thereby increasing surface area, and significantly speeding up the decellularization process. The use of minced tissue also increases research accessibility by eliminating the need for specialized perfusion bioreactors to keep the whole heart intact, and instead utilizes basic tools for decellularization that are available in most research labs (stir bars/orbital shakers). Similar to whole heart decellularization, the minced tissue approach often uses detergents such as 1\% SDS and 1\% Triton $\mathrm{X}-100$.

The properties linked to tissue origin such as species source and donor age also demonstrate differential responses to different decellularization protocols. An example of the influence of tissue source is evidenced by a study in which a protocol that had been optimized to decellularized fresh porcine hearts was not effective in the complete decellularization of the same sized cadaveric human hearts (Johnson et al., 2014). Cadaveric hearts required much longer SDS treatment in addition to isopropyl alcohol and a DNase/RNase solution containing $\mathrm{HCl}, \mathrm{MgCl}, \mathrm{CaCl}$, and $\mathrm{NaCl}$ at
$\mathrm{pH}$ 7.4. Even still, there was significant patient-to-patient variability, which increased the difficulty in processing the human tissues. These differences could possibly be explained by the variability in age amongst the cadaveric hearts as well as the difference in age between the human and porcine hearts. Age increases cardiac tissue stiffening through fibrosis and increased ECM cross-linking (Johnson et al., 2014). Similarly, fetal rat and porcine hearts required a more diluted concentration of SDS and Triton X-100 compared to their adult counterparts (Williams et al., 2014; Fong et al., 2016; Wang et al., 2020; Wang et al., 2021). However, there are rare instances in which a protocol has been developed that works reasonably well for tissues of disparate ages. Silva et al. successfully developed a protocol that enabled the parallel decellularization of both fetal and adult rat hearts using freeze-thaw, physical agitation, hypotonic buffer (Tris $\mathrm{HCl}+$ EDTA), 0.2\% SDS, and DNase (Silva et al., 2016). In summary, there are many variables that influence the effectiveness of a cardiac decellularization protocol that heavily depend on the tissue species, age, and final end application.

\subsection{Decellularization Methods for Skeletal Tissue}

Over the course of the last decade, an increasing number of different protocols have been developed and modified for skeletal muscle decellularization (Table 2). When the field was relatively young, the most common decellularization agent was trypsin, which was often used in combination with detergents such as SDS, Triton X-100, and Sodium Deoxycholate (SDC). The use of trypsin eventually declined when the destructive properties of this enzyme became well-known (Miersch et al., 2018; Sharma et al., 2019). While a harsh decellularization treatment is highly efficient at removing cellular debris and DNA from the tissue, it can also remove essential ECM proteins and proteoglycans. The preservation of the ECM is especially relevant for skeletal muscle, which, based on a proteomic analysis of 21 different organs, has over a 10 -fold greater number of unique proteins compared to all other organs (Raffa et al., 2020). The ECM serves as an important driver of cell-fate and tissue regeneration in the healing response of skeletal muscle following injury (Herrera et al., 2018; Csapo et al., 2020; Nicolas et al., 2020). Therefore, like cardiac decellularization protocols, methods for obtaining decellularized skeletal muscle ECM require a balance of removing cellular material while best conserving the biophysical components and integrity of the complex skeletal muscle matrix (Grisales et al., 2021).

There exists a wide variety of approaches for obtaining decellularized skeletal muscle, which range from the more aggressive enzymatic treatments to the use of comparatively mild depolymerizing agents such as Latrunculin B (LatB). Detergent-based methods have historically dominated the field of skeletal muscle decellularization. The most widely used detergents such as SDS, Triton X-100, and SDC are used for their surfactant properties which disrupt the lipid bilayer of cell membranes to facilitate cell lysis (Lichtenberg et al., 2013). More specifically, SDS acts by solubilizing the cytoplasmic and nuclear membranes, while both Triton X-100 and SDC work by targeting 
TABLE 2 | Skeletal muscle decellularization protocols.

\begin{tabular}{|c|c|c|c|c|c|}
\hline Application & Species & $\begin{array}{l}\text { Tissue } \\
\text { Form }\end{array}$ & $\begin{array}{l}\text { Decellularization } \\
\text { Treatments }\end{array}$ & Study Findings & Citation \\
\hline $\begin{array}{l}\text { Comp/ Topo/ } \\
\text { Mech }\end{array}$ & Porcine & Minced & SDS + Triton & $\begin{array}{l}\mathrm{dECM} \text { bioink improved muscle regeneration when compared to collagen } \\
\text { bioink. }\end{array}$ & Choi et al. (2016) \\
\hline Comp/ Mech & Rat & Whole & $\begin{array}{l}\text { Free/thaw + Trypsin + } \\
\text { Triton }\end{array}$ & $\begin{array}{l}\text { In vivo transplantation of muscle derived ECM showed a large fibrotic mass } \\
\text { production } 6 \text { months post-surgery. }\end{array}$ & $\begin{array}{l}\text { Corona et al. } \\
(2013)\end{array}$ \\
\hline Comp/ Mech & Rabbit & Whole & $\mathrm{LatB}+\mathrm{KCl} / \mathrm{KI}$ & $\begin{array}{l}\text { Xenotransplant scaffold showed low immunogenic response in vitro and } \\
\text { in vivo, suggesting immunosuppressive and anti-inflammatory effects. }\end{array}$ & $\begin{array}{l}\text { Fishman et al. } \\
\text { (2013) }\end{array}$ \\
\hline Comp/ Topo & Porcine & Minced & $\begin{array}{l}\text { SDS Trypsin + } \\
\text { Triton + SDC }\end{array}$ & $\begin{array}{l}\text { Exploitation of PDMS elastic property allowed anisotropic reorganization of } \\
3 \mathrm{D} \text { skeletal muscle dECM; construct supports de novo muscle } \\
\text { regeneration. }\end{array}$ & Jin et al. (2021a) \\
\hline Comp/ Mech & Rat & Whole & SDS & $\begin{array}{l}\mathrm{dECM} \text { and minced muscle scaffolds improved recovery in VML injury } \\
\text { animal model. }\end{array}$ & $\begin{array}{l}\text { Kasukonis et al. } \\
(2016 a)\end{array}$ \\
\hline Comp/ Mech & Rat & Whole & SDS & Developed an infusion bioreactor for skeletal muscle decellularization. & $\begin{array}{l}\text { Kasukonis et al. } \\
(2016 b)\end{array}$ \\
\hline Comp/ Mech & Rabbit & Minced & SDS + Triton & $\begin{array}{l}\text { Development of cell-free scaffold comprised of decellularized skeletal } \\
\text { muscle and IGF-1 promotes tissue regeneration in vivo and in situ. }\end{array}$ & Lee et al. (2020) \\
\hline Comp & Human & Minced & $\mathrm{LatB}+\mathrm{KCl} / \mathrm{KI} \mathrm{SDC}$ SDS & $\begin{array}{l}\text { Harsher SDS treatment shown to decellularize human skeletal muscle } \\
\text { better than less harsh LatB }+\mathrm{KCl} / \mathrm{KI} \text { and SDC treatments. }\end{array}$ & Naik et al. (2020) \\
\hline Comp/Topo & Bovine & Minced & $\begin{array}{l}\text { Freeze-thaw + Triton } \\
+\mathrm{NH} 4 \mathrm{OH}\end{array}$ & $\begin{array}{l}\text { Electrospun PCL/dECM scaffold supported myogenesis in vitro; scaffold } \\
\text { implanted in murine VML in vivo model showed increased anti- } \\
\text { inflammatory activity and myofiber regeneration. }\end{array}$ & Patel et al. (2020) \\
\hline Comp/Mech & Chicken & Whole & $\begin{array}{l}\text { LatB }+\mathrm{KCl} / \mathrm{KI} \text { Triton } \\
\text { Triton }+\mathrm{SDS}\end{array}$ & $\begin{array}{l}\text { LatB }+\mathrm{KCl} / \mathrm{KI} \text { protocol was most efficient for decellularization compared to } \\
\text { competing methods, reducing DNA, myosin and actin content significantly. }\end{array}$ & Reyna et al. (2020) \\
\hline Comp/ Mech & Bovine & Minced & $\begin{array}{l}\text { Freeze/thaw + Triton + } \\
\mathrm{NH} 4 \mathrm{OH}\end{array}$ & $\begin{array}{l}\text { In vitro studies of dECM gelloid supported MSC survival, expansion, } \\
\text { trophic factor secretion, immunomodulation, and myogenic protein } \\
\text { expression. }\end{array}$ & $\begin{array}{l}\text { Talovic et al. } \\
\text { (2019) }\end{array}$ \\
\hline Comp/ Mech & Rat & Whole & LatB + KCl/KI SDC SDS & $\begin{array}{l}\text { Implanted dECM from three different protocols in immune competent } \\
\text { model of VML generated functional muscle, vasculature, nervous fibers. }\end{array}$ & $\begin{array}{l}\text { Urciuolo et al. } \\
(2018)\end{array}$ \\
\hline Comp & Dog & Whole & Trypsin + SDC + Triton & $\begin{array}{l}\text { Comparing decellularized small intestine and skeletal muscle regenerative } \\
\text { outcomes shows no difference after prolonged period. }\end{array}$ & Wolf et al. (2012) \\
\hline Comp & Porcine & Whole & Trypsin + SDS + Triton & $\begin{array}{l}\text { In vivo implantation of dECM in partial thickness abdominal wall defects in } \\
\text { rats showed neovascularization, myogenesis, and recellularization. }\end{array}$ & Zhang et al. (2016) \\
\hline $\begin{array}{l}\text { Topo/ Comp/ } \\
\text { Mech }\end{array}$ & Porcine & Minced & SDS + Triton & $\begin{array}{l}\text { dECM coating significantly improved myotube and myogenic differentiation } \\
\text { compared with collagen/non-coated surfaces. }\end{array}$ & Choi et al. (2018) \\
\hline $\begin{array}{l}\text { Topo/ Comp/ } \\
\text { Mech }\end{array}$ & Porcine & Minced & SDS + Triton & $\begin{array}{l}\text { The 3D printed muscle constructs exhibited high cell viability without } \\
\text { hypoxia; enhanced de novo muscle formation in a VML rat model. }\end{array}$ & Choi et al. (2019) \\
\hline Topo/ Comp & Porcine & Minced & SDS & $\begin{array}{l}\text { Thermally drawn PCL/dECM mix implanted in VML, a model showed } \\
\text { induced de novo muscle regeneration. }\end{array}$ & Jin et al. (2021b) \\
\hline $\begin{array}{l}\text { Topo/ Comp/ } \\
\text { Mech }\end{array}$ & Porcine & Minced & SDS + Triton & $\begin{array}{l}\text { In vitro cellular responses showed successful recellularization on 3D- } \\
\text { printed dECM-based structure. }\end{array}$ & Kim et al. (2020) \\
\hline $\begin{array}{l}\text { Topo/ Comp/ } \\
\text { Mech }\end{array}$ & Porcine & Minced & SDS + Triton & $\begin{array}{l}\text { Photo-crosslinkable, dECM/PVA hydrogel, 3D-printed self-aligned skeletal } \\
\text { muscle construct showed rapid restoration of muscle function. }\end{array}$ & Lee et al. (2021) \\
\hline $\begin{array}{l}\text { Topo/ Comp/ } \\
\text { Mech }\end{array}$ & Bovine & Minced & $\begin{array}{l}\text { Freeze-thaw + Triton }+ \\
\mathrm{NH} 4 \mathrm{OH}\end{array}$ & $\begin{array}{l}\text { Aligned electrospun dECM/PCL scaffolds supported satellite cell growth, } \\
\text { myogenic protein expression and myokine production. }\end{array}$ & Patel et al. (2019) \\
\hline Topo & Rabbit & Minced & Trypsin + Triton & $\begin{array}{l}\text { C2C12 myoblasts recellularization affected by degree of crosslinking } \\
\text { (stiffness) and alignment (topography) of electrospun dECM scaffold. }\end{array}$ & $\begin{array}{l}\text { Smoak et al. } \\
(2021)\end{array}$ \\
\hline
\end{tabular}

the lipid-protein and lipid-lipid interactions of cells (Reyna et al., 2020). The mechanism of action of these different reagents can dictate the efficiency of cellular removal.

A treatment of $1 \%$ SDS has been used in numerous studies as the main decellularization agent for minced muscle and was commonly reported to remove approximately $98 \%$ total DNA (Choi et al., 2016; Kim et al., 2020; Lee et al., 2020; Jin et al., 2021a; Jin et al., 2021b). In contrast, groups that used non-SDS agents such as SDC and ammonium hydroxide reported less efficient cellular removal with a range of 50-80\% total DNA (Piccoli et al., 2017; Patel et al., 2019; Smoak et al., 2019; Talovic et al., 2019; Jin et al., 2021a). Removal of cellular material and DNA content is critical in the downstream application of decellularized tissues to avoid complications triggered by the host immune response.
Several residual components can lead to the activation of an immune response following allo- and xenotransplantation including any remaining DNA fragments, human leukocyte antigens (HLA), and major histocompatibility complex (MHC) molecules (Quake, 2011; Nakamura et al., 2019). However, while detergent-based methods are effective in clearing the tissue of cellular debris, these reagents may also remove key bioactive ECM proteins and proteoglycans (Gilbert et al., 2009; Crapo et al., 2011; Soto-Gutierrez et al., 2011). Therefore, skeletal muscle decellularization protocols must balance the removal of cellular materials with maintaining any essential cell signaling components contained within the ECM.

To mitigate the disruptive properties of detergent-based methods, gentler decellularization approaches have been developed for skeletal 


\section{Minced Skeletal Muscle}
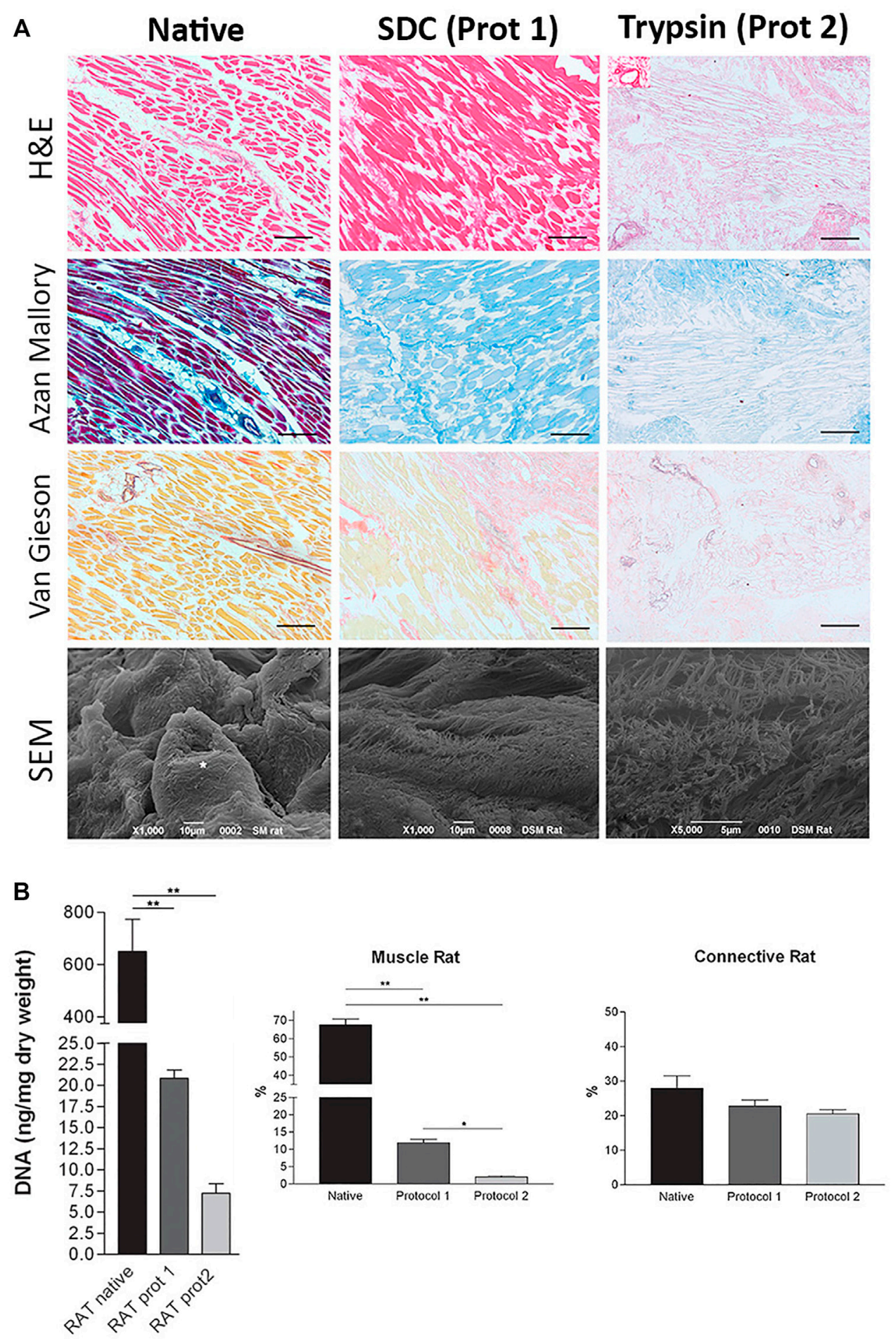

FIGURE 2 | Minced tissue decellularization protocols and outcomes (A) Tissue morphology from top to bottom: H\&E staining, Azan Mallory stains, Van Gieson stains, and SEM images of minced tissues before (Native, column 1) and after decellularization with SDC (Protocol 1, SDC + DNase I, column 2) and Trypsin (Protocol 2, Trypsin/EDTA + Triton X-NH4OH, column 3) protocols (B) DNA, muscle content, and connective tissue content before and after decellularization using protocol one and protocol 2. Figures A,B are adapted from "Decellularized Human Skeletal Muscle as Biologic scaffold for Reconstructive Surgery" by Porzionato et al. (2015) licensed under CC BY 4.0. 
muscle. Utilizing a natural toxin produced by aquatic sponges (Spector et al., 1983), Gillies et al. demonstrated a decellularization procedure using LatB together with hyper- and hypotonic salt solutions (Gillies et al., 2011). The LatB treatment depolymerized the actin-myosin filaments of whole skeletal muscle structures in mice, while actively preserving the ECM components including GAGs and collagen (Gillies et al., 2011). Because this protocol is also effective at removing DNA (95\% removal, $2.92 \pm$ $0.14 \mathrm{mg} / \mathrm{mg}$ dry weight in native muscle to $0.12 \pm 0.01 \mathrm{mg} / \mathrm{mg}$ dry weight in decellularized muscle), LatB decellularization is increasingly preferred in studies that are highly dependent on preserving dECM bioactivity. However, unlike SDS, it has been suggested that the LatB protocol does not scale well and is less effective at decellularizing larger tissues (Naik et al., 2020). Naik et al. demonstrated that the overall difference in tissue size alters the effectiveness of the decellularization reagents (Naik et al., 2020) and hence, a milder LatB protocol is insufficient in completely eliminating nuclear materials in larger whole human muscles as compared to smaller whole murine muscles.

The decellularization of skeletal muscle is generally approached using either minced or whole tissues, each with their own corresponding advantages and disadvantages. Smaller minced tissues provide a larger surface area for cell lysis compared to larger whole tissues which aides in the effective removal of nuclear material but may sacrifice the spatial context of their original anatomical structures (Figure 2A,B). Conversely, decellularized whole tissues preserve the greater structure of the native tissue, but due to diffusion limitations, whole tissue protocols often require a harsher treatment agent, or the use of perfusion techniques to avoid extended decellularization times. However, the end application of the decellularized tissue can help determine which format is most appropriate. Whole tissue decellularization is useful in whole organ transplantation or in the replacement of large sections of injured skeletal muscle, whereas minced tissue decellularization is often used when the macrostructure is not a priority such as in bioink production for $3 \mathrm{D}$ printing. Because it is less vital to preserve the ECM spatial architecture for bioink production, these protocols often utilize higher concentrations of SDS ( $\geq 1 \%$ SDS), compared to whole skeletal muscle decellularization, which is usually performed with perfused 0.25\% SDS or LatB (Choi et al., 2016; Kim et al., 2020; Lee et al., 2020; Jin et al., 2021a; Jin et al., 2021b).

In addition to the main decellularizing reagents, many protocols include supplementary chemicals to ensure complete decellularization. For instance, DNase is frequently used after the primary decellularization step to further assist in the removal of residual DNA (Gillies et al., 2011; Zhang et al., 2016; Urciuolo et al., 2018). Likewise, chloroform and isopropyl alcohol are regularly used to extract unwanted lipids from the native tissue before decellularization (Wolf et al., 2012; Ungerleider et al., 2015). In the final stages of the protocol, once a tissue has been decellularized, washes with sterilizing and anti-mycotic agents such as penicillin and streptomycin, (Merritt et al., 2010; Kasukonis B. et al., 2016; Kasukonis B. M. et al., 2016; Jin et al., 2021a; Jin et al., 2021b), peracetic acid, (Wolf et al., 2012; Zhang et al., 2016; Choi et al., 2019), and ethanol (Choi et al., 2019) are used. Lastly, many groups administer EDTA in series or in combination with the first few decellularizing agents to help prevent clot formation as the blood is removed from the tissue vasculature (Gillies et al., 2011; Miranda et al., 2021). Although these supplementary chemicals contribute to a more complete decellularization, they may also impact the ECM retention, myofiber morphology, and overall structural integrity of decellularized tissues. Therefore, the rule of thumb is to use the fewest agents possible and the shortest decellularization times to achieve the targeted $\mathrm{dECM}$ properties.

\section{BIOPHYSICAL PROPERTIES: ECM COMPOSITION}

The ECM is composed of a highly complex network of macromolecules that provide a supportive structural and functional niche for the surrounding cells. While the composition and respective biological functions of ECM are still being investigated, the components of ECM can be broken down into three main groups: glycoproteins, GAGs, and proteoglycans (Figure 3A). Glycoproteins, such as collagen, elastin, laminin, and fibronectin, make up the bulk of the ECM and provide the primary structural support and binding sites for cells (Silva et al., 2016) (Figure 3B,C). GAGs play a crucial role in modulating biochemical processes such as cell proliferation, migration, and wound repair (Puri et al., 2020). Proteoglycans have GAGs bound to their core and are one of the most complex and multifunctional molecules in cell biology (Walimbe and Panitch, 2020). Some of the reported functions of proteoglycans include growth factor sequestering, control of collagen fibrillogenesis, regulation of angiogenesis, and modulation of cell adhesion, proliferation, and pathway regulation (Walimbe and Panitch, 2020). The ECM is a highly dynamic structure that is constantly changing in response to environmental cues from growth, development, disease, injury, and repair.

\subsection{Cardiac dECM Composition}

The investigation of cardiac ECM composition was historically challenging due to the low solubility of the tissue's macromolecules and their post-translational modifications (Chang et al., 2016). However, advancements in ECM protein enrichment and technology have enabled a more complete investigation of cardiac ECM (Lindsey et al., 2018). Johnson et al. identified over 200 distinct cardiac ECM proteins in decellularized human hearts, the most prominent being collagen I, collagen IV, fibrillin 1 , collagen V, collagen VI, laminin, and perlecan (Johnson et al., 2016).

The composition of cardiac ECM is also dependent on age. Multiple groups have compared the composition of cardiac ECM at varying stages of development and maturation (Williams et al., 2014; Fong et al., 2016; Johnson et al., 2016; Silva et al., 2016). Of the 15 most abundant cardiac proteins detected in rat hearts, adult ECM contained 38\% collagen I, 18\% fibrillin, 14\% laminin, $8 \%$ perlecan, while fetal hearts contained $26 \%$ fibronectin, $13 \%$ fibrillin, 12\% perlecan, 11\% collagen I (Figure 3D) (Williams et al., 2014). Furthermore, fibrillin-2 and emilin-1 were among the top 15 most abundant proteins in fetal cardiac ECM, but not in adult cardiac ECM. These differences in composition provide 
A
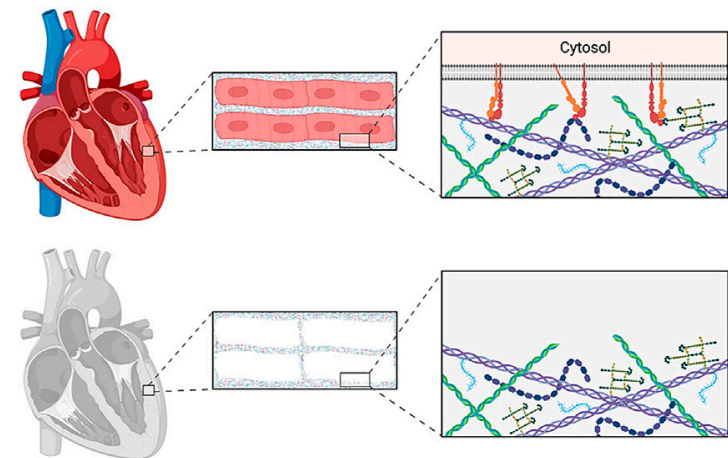

D

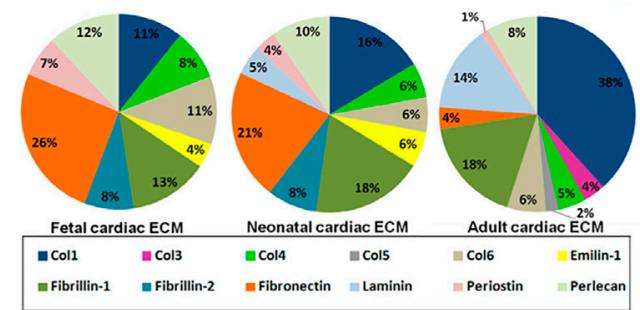

E

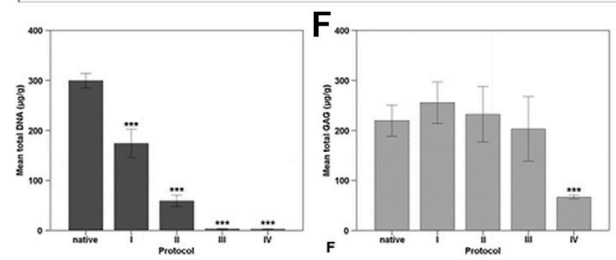

B Cardiac Elastin

B Dayo Day 5 Day 7 Dayo Cardiac Collagen

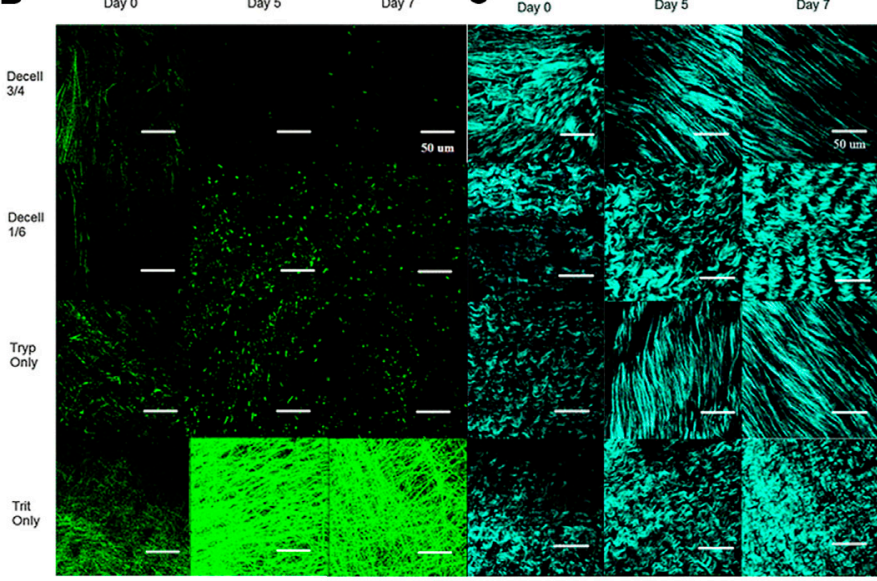

G
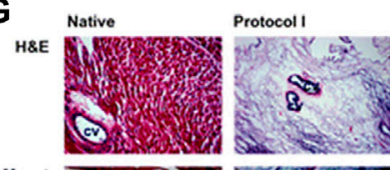

Protocol II

Protocol III

Protocol IV

Movat
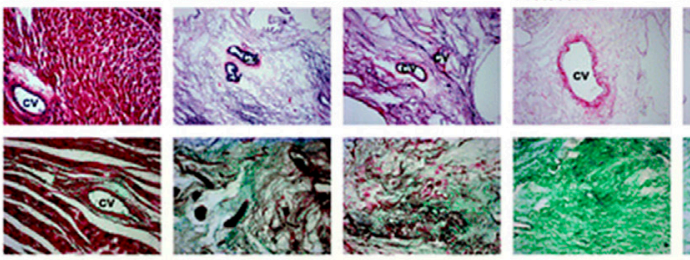

$\underset{f G}{\text { PSR }}$
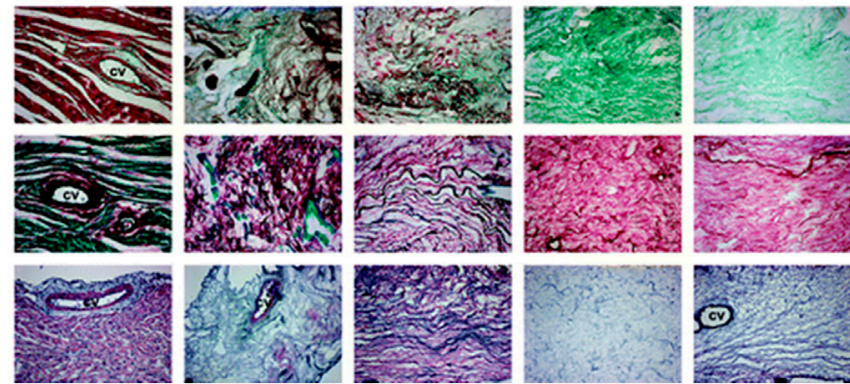

FIGURE 3 | Cardiac extracellular matrix composition (A) Schematic of cardiac tissue before and after decellularization (B-C) Extracellular matrix microstructure of decellularized whole porcine hearts following four different decellularization protocols. Decell 3/4: Trypsin for 3 days followed by Triton for 4 days. Decell 1/6: Trypsin 1 day, Triton 6 days. Tryp Only: Trypsin 7 days. Trit Only: Triton 7 days. Scale bar $50 \mu m$ (B) Elastin microstructure. Two photon fluorescence (C) Collagen microstructure. Second harmonic generation imaging (D-F) Rat myocardial ECM morphology and composition before (native) and after whole heart decellularization using four different decellularization protocols. Briefly, Protocol I: SDS and Triton. Protocol II: Trypsin, EDTA, deoxycholic acid (DCA), and acetic acid. Protocol III: Glycerol, NaN $\mathrm{N}_{3}$, EDTA, NaCl, DCA, SDS, and Triton. Protocol IV: SDS, DCA, NaN 3 , Glycerol, EDTA, Saponin, DNase I, and MgCl (D) The 15 most abundant proteins in cardiac ECM measured by liquid chromatography-mass spectrometry (LC-MS/MS) at each developmental age (E) Mean DNA content and (F) mean GAG content of the native whole rat heart before (native) and after decellularization using protocols I - IV (G) Rat myocardial ECM morphology from top to bottom: Hematoxylin and Eosin (H\&E) staining, Movat Pentachrome (Movat), picrosirius red and fast green (PSR \& FG), and alpha-actin of rat hearts before (Native, column 1) and after whole heart decellularization (Protocols I-IV, columns 2-5). CV, coronary vessel. $\times 100$ magnification. Figure A is created using BioRender.com. Figures B, C are adapted with permission from Merna et al. (2013). Figure D is adapted with permission from Williams et al. (2014). Figures E-G are adapted with permission from Akhyari et al. (2011).

insight into the supportive niche of the developing heart and may serve as a blueprint for ideal ECM mixtures to use for modulating regeneration.

\subsubsection{How Different Protocols Affect Cardiac dECM Composition}

Maintaining cardiac ECM proteins while thoroughly removing native DNA and cellular fragments is crucial for the success of many downstream applications. Most groups validate their decellularization protocol by quantifying the total DNA and GAG content that is left following decellularization. It is widely accepted that a protocol that results in less than $50 \mathrm{ng}$ of double-stranded DNA per mg of tissue dry weight is effective in clearing the tissue of nuclear debris, although it should be noted that many groups measure and report residual DNA content differently (concentration, fragment length, staining) (Gilpin and Yang, 2017). However, reagents that thoroughly remove DNA and cellular debris often also disrupt GAG content. Akhyari et al. used a long duration protocol (5.7 days) with $1 \%$ SDS $+1 \%$ DCA that produced tissues with less than $0.5 \%$ residual DNA, but significantly decreased GAGs by almost $70 \%$ compared to native content (Figure 3E-G) (Akhyari et al., 2011). In contrast, when the same group used a short duration protocol $(4.75 \mathrm{~h})$ with $1 \%$ SDS and $1 \%$ Triton X-100, the resulting tissues showed no decrease in GAGs $(255.53 \mu \mathrm{g} / \mathrm{g}$ vs $219.33 \mu \mathrm{g} / \mathrm{g}$ native); however, approximately $13.9 \%$ residual DNA was still present. 
Fortunately, there are combination protocols that have been shown to strike a balance between GAG retention and DNA removal. Wainwright et al. used a mixture of chemical, physical, and enzymatic decellularization techniques to maintain GAGs while also adequately removing residual DNA (0.66 ng DNA/mg vs $8.48 \mathrm{ng}$ DNA/mg native, a $92 \%$ decrease) (Wainwright et al., 2010). A multi-step protocol by $\mathrm{Lu}$ et al. used trypsin, triton, cycles of freeze/thaw, SDS, deoxycholic acid, peracetic acid, and ethanol to produce ECM with preserved 3D architecture and filament structure while still achieving $~ 97 \%$ DNA removal (Lu et al., 2013). Alternatively, an adequate retention/removal balance has been achieved with simpler protocols that use classically damaging reagents for a short amount of time, followed by thorough washing to clear the matrix. This includes one of the most published cardiac decellularization approaches which uses $1 \%$ SDS and $1 \%$ Triton X-100 with several deionized water or PBS rinses (Ott et al., 2008; Robertson et al., 2014; Williams et al., 2014; Hochman-Mendez et al., 2020; Wang et al., 2020; Basara et al., 2021; Mousavi et al., 2021; Tsui et al., 2021). This approach has been demonstrated to have an adequate balance of DNA removal while maintaining ECM composition.

\subsubsection{How Cardiac dECM Composition Affects Cell Behavior In Vitro}

The ECM is a potent modulator of cell behavior and recent efforts in the field of cardiac dECM have focused on the use of this material to guide cells in vitro. Through the sophisticated regulation of soluble factors and cell signaling pathways, the ECM components can guide proliferation, fate specification, and migration. (Mesquita et al., 2021). However, there has been a gradual shift away from classical whole organ decellularization towards protocols that utilize ground or solubilized cardiac ECM. This pivot was thought to have been fueled by growing evidence that the concentration and bioactivity of $\mathrm{dECM}$ components played a greater role in guiding recellularization than the overall ultrastructure.

A well-known bottleneck of cardiac tissue engineering has been the limited proliferation potential of cardiomyocytes. However, ground or solubilized cardiac ECM serves as an instructive cell culture additive that can enhance cardiomyocyte proliferation. Williams et al. cultured ventricular cells on solubilized AECM and analyzed attachment, proliferation, and maturation (Williams et al., 2014). They found that fetal cardiac ECM was associated with greater cardiomyocyte adherence and proliferation in comparison to the Poly-L-Lysine (PLL) control and adult ECM. ECM components such as periostin and collagen IV were more abundant in the fetal ECM compared to adult, suggesting that these likely played a decisive role in enhancing myocyte proliferation.

Cardiac ECM has also been shown to improve cardiomyocyte differentiation and maturation (Das et al., 2019; HochmanMendez et al., 2020; Mesquita et al., 2021). Hochman-Mendez et al. cultured human embryonic stem cell-derived cardiomyocytes (hESC-CM) with dECM particles (HochmanMendez et al., 2020). hESC-CMs attached to the basement membrane and demonstrated enhanced maturation characteristics such electrical coupling, gap junctions, and increased sarcomere lengths. Das et al. showed that neonatal rat cardiomyocytes grown in $\mathrm{DECM}$ bioink rather than a single ECM protein of just collagen alone, facilitated a cell-material cross-talk that drove cell morphology and function (Das et al., 2019).

Not only can cardiac ECM improve maturation of stem cellderived cardiomyocytes, but it can also guide phenotype specificity. Most cardiomyocyte differentiation protocols generate ventricular-like cells, but atrial-like cardiomyocytes are also needed for therapeutics and disease modeling. In order to generate atrial-like cardiomyocytes, high concentrations of retinoic acid are used; however, this agent is unstable in serum-free media, making standardized differentiation protocols difficult. Mesquita et al. demonstrated the use of chamber-specific powdered ECM to drive cardiomyocyte subtype differentiation (Mesquita et al., 2021). When human iPSCs were cultured with human atrial dECM particles, the cells expressed more atrial-like characteristics as verified by proteomics, action potentials, and gene expression. Similarly, human iPSCs cultured with ventricular ECM particles resulted in more mature ventricular CMs, as supported by the electrophysiological characterization, compared to iPSCs differentiated without ECM (Mesquita et al., 2021).

\subsubsection{How Cardiac dECM Composition Affects Cell Regeneration In Vivo}

Historically, cardiac dECM was viewed as a potential therapeutic in the form of a transplantable whole organ. The idea was to recellularize a full dECM heart with patient-specific cells to provide an autologous organ for transplantation, eliminating the need for lifelong anti-rejection medication. The cell requirements needed to repopulate an entire human heart is a major rate-limiting step and led to the use of dECM segments for use as cardiac patches, which showed promise as a post myocardial infarction (MI) treatment. Shah et al. implanted a $300 \mu \mathrm{m}$ slice of decellularized porcine myocardium with or without rat adipose stem cells into rats $20 \mathrm{~min}$ after coronary artery ligation (Shah et al., 2018). Hearts treated with the dECM patch had increased vascularization and significantly more cells present compared to cells delivered via direct injection after 1 week. While the use of intact $\mathrm{dECM}$ is still explored for patches, other forms of $\mathrm{dECM}$ are being developed for greater control over the decellularization and recellularization processes.

It is well-understood that the retention of ECM protein composition and integrity are essential for cell adherence, proliferation, and maturation. However, preserving protein bioactivity may come at the expense of residual DNA and cell fragments, which can elicit an immune response, thereby limiting the ECMs regenerative potential (Keane et al., 2012). Fortunately, in vivo rat and mouse studies primarily use cardiac $\mathrm{AECM}$ in a ground or solubilized form, which enables more efficient removal of cell debris due to optimizing surface area and diffusion distances (Singelyn et al., 2012; Wang et al., 2019; Wang et al., 2020). Without the need to keep the whole heart architecture intact, protocols using minced, ground, or solubilized ECM can more thoroughly remove residual DNA and cell fragments 
without inducing significant changes to the overall ECM composition.

dECM injectables have demonstrated translational efficacy in small animal models of cardiac injury (Singelyn et al., 2012). Wang, Z. et al. injected adult or neonatal mouse dECM suspended in saline into the epicardium of mice immediately following induced MI (Wang et al., 2019). Neonatal dECM was shown to improve cardiac function, reduce fibrosis, and promote angiogenesis. Adult $\mathrm{dECM}$ did not share the regenerative capabilities of the neonatal $\mathrm{DECM}$, and in many instances, performed no better than the saline control. This study, and similar studies that use injectable dECMs, highlight the functional benefits of solubilized DECM as a material to mitigate the negative remodeling that often follows MI. Moreover, this underscores a paradigm shift away from conventional adult-derived ECM materials and towards a future that looks further into the advantages and understanding of neonatal-derived dECMs.

Another form of solubilized DECM that has been growing in popularity is bioinks that are used to generate cardiac patches. Bejleri et al. bioprinted a GelMA-dECM patch and implanted it onto healthy rat epicardium for 14 days (Bejleri et al., 2018). Histological analysis showed that the patch became vascularized and integrated with the host myocardium. Jang et al. also bioprinted a cardiac patch containing human DECM and polycaprolactone (PCL), with alternating layers of cardiac progenitor cells and mesenchymal stem cells (Jang et al., 2017). The patches were first implanted subcutaneously into the abdomen of the rat for host vascularization. After 28 days, the patch was explanted and then implanted onto the epicardium of rats that had an induced MI 7 days prior. This alternating layered approach led to improved cardiac function, attenuated fibrosis, greater cell migration out from the transplanted patch into the damaged tissue, and enhanced vasculogenesis and myogenesis. These works demonstrate how cardiac dECM can be solubilized and used as a supportive niche to promote a proregenerative and mitigate a pro-fibrotic healing response following cardiac injury.

Lastly, the cardiac dECM is rich with cytokines and small molecules that modulate angiogenesis, survival, cell recruitment and the cellular response to inflammation. Decellularized porcine myocardium was found to contain vascular growth factors such as VEGF-A, VEGF-C, and FGF-1, cardiokines including PDGF, HGF, and endoglin, as well as factors involved in the inflammation such as G-CSF and IL-8 (Methe et al., 2014). While these residual factors modulate a range of pro-survival and pro-recruitment functions, they also exhibit batch-to-batch variability and present an ongoing challenge in the standardization of decellularization protocols.

\subsection{Skeletal Muscle dECM Composition}

The ECM of native skeletal muscle is composed of a combination of proteins and proteoglycans such as collagen, elastin, laminin, fibronectin and GAGs (Csapo et al., 2020). These components serve as modulatory binding sites, structural materials, and gene regulators for the native muscle and if preserved correctly, can serve these same functions as a decellularized material for skeletal muscle regenerative applications (Csapo et al., 2020). However, due to the wide range of decellularization protocols, the resulting dECM composition varies and hence the regenerative capacity of these materials will also vary.

\subsubsection{How Different Protocols Affect Skeletal Muscle dECM Composition and Cell Interactions - Trypsin}

Trypsin is a serine protease secreted by the pancreas to aid in the digestion of proteins (Miersch et al., 2018). In cell culture, trypsin is commonly used for detaching adherent cells during cell passaging (Sharma et al., 2019) as it disrupts the cell-ECM bonds. For this reason, trypsin is also used as a dissociation agent in skeletal muscle decellularization. However, due to its strong digestive properties, trypsin is also effective in removing essential ECM components like collagen and GAGs which present a challenge for downstream applications that rely on interactions with these components.

Wolf et al. established a decellularization protocol for whole muscles using $0.1 \%$ Trypsin, 2\% SDC and 1\% Triton X-100 (Wolf et al., 2012). ECM characterization using Herovici's and Movat's Pentachrome stains detected the presence of collagen and elastin, while immunostains of the basement membrane showed the preservation of laminin, type IV collagen, and fibronectin. Although the stains showed some ECM presence, the stains also revealed the dysmorphism of the physical structures in decellularized skeletal muscles. Furthermore, only 20\% of sulfated GAGs (sGAGs) were retained in decellularized skeletal muscles when compared to native skeletal muscles. When these muscle dECMs were seeded with human perivascular stem cells, $\mathrm{NIH}$ 3T3 mouse fibroblasts, and $\mathrm{C} 2 \mathrm{C} 12$ mouse myoblasts, cellular proliferation was observed on the surface of the decellularized tissue for all cell types. Additionally, the cultured $\mathrm{C} 2 \mathrm{C} 12 \mathrm{~s}$ further differentiated into mature myotubes. In contrast, cellular metabolism quantified using Alamar Blue assay indicated higher metabolic activity in the tissue culture flask control compared to cells grown on the decellularized scaffold. In vivo implantation of the decellularized scaffold in a rat abdominal wall defect showed dense accumulation of regenerating cells, angiogenesis, and myogenesis around the scaffold surface as shown by histological analyses. Corona et al. used a similar combination of reagents on whole rat tibialis anterior (TA) muscles and showed enhanced cell proliferation of muscle satellite cells in vitro, but limited myogenesis when implanted into a volumetric muscle loss (VML) injury (Corona et al., 2013).

In contrast, greater in vivo healing outcomes were reported by Zhang et al. who combined $0.02 \%$ trypsin with $0.1 \%$ SDS and $1 \%$ Triton X-100 to perfusion decellularize whole porcine skeletal muscles (Zhang et al., 2016). ECM characterization of the decellularized tissue validated the retention of laminin, type IV collagen, fibronectin, and elastin. Similarly, sGAG quantification of native versus decellularized tissues corresponded to a preservation of roughly $20 \%$ sGAGs in the decellularized tissues. The culture and differentiation of $\mathrm{C} 2 \mathrm{C} 12$ myoblasts on the $\mathrm{dECM}$ scaffold demonstrated improved myogenesis including greater fiber diameter, fusion index, and increased metabolism compared to the tissue culture plastic controls. In a VML injury model involving a rat abdominal wall defect, the transplanted dECM scaffold showed abundant cellular infiltration around the 


\section{Whole Skeletal Muscle}

A

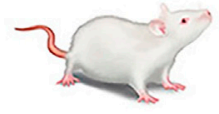

Male Sprague Dawey rats.

$\downarrow$

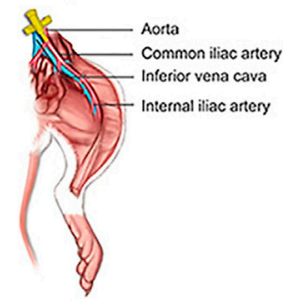

$\downarrow$
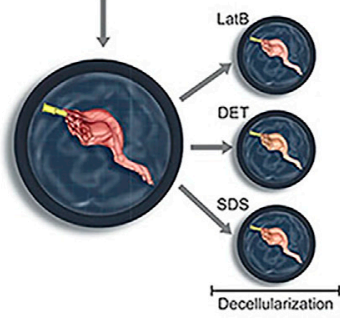

D

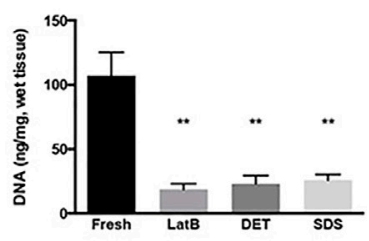

B

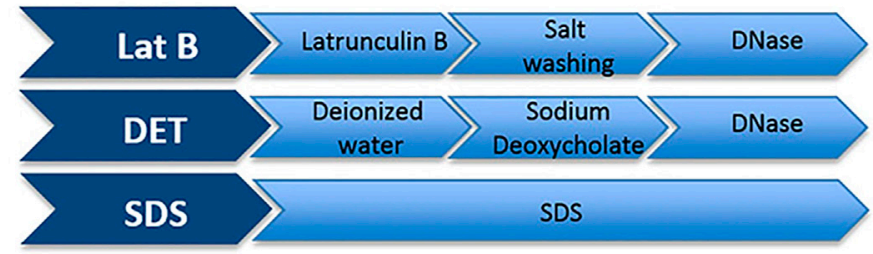

C
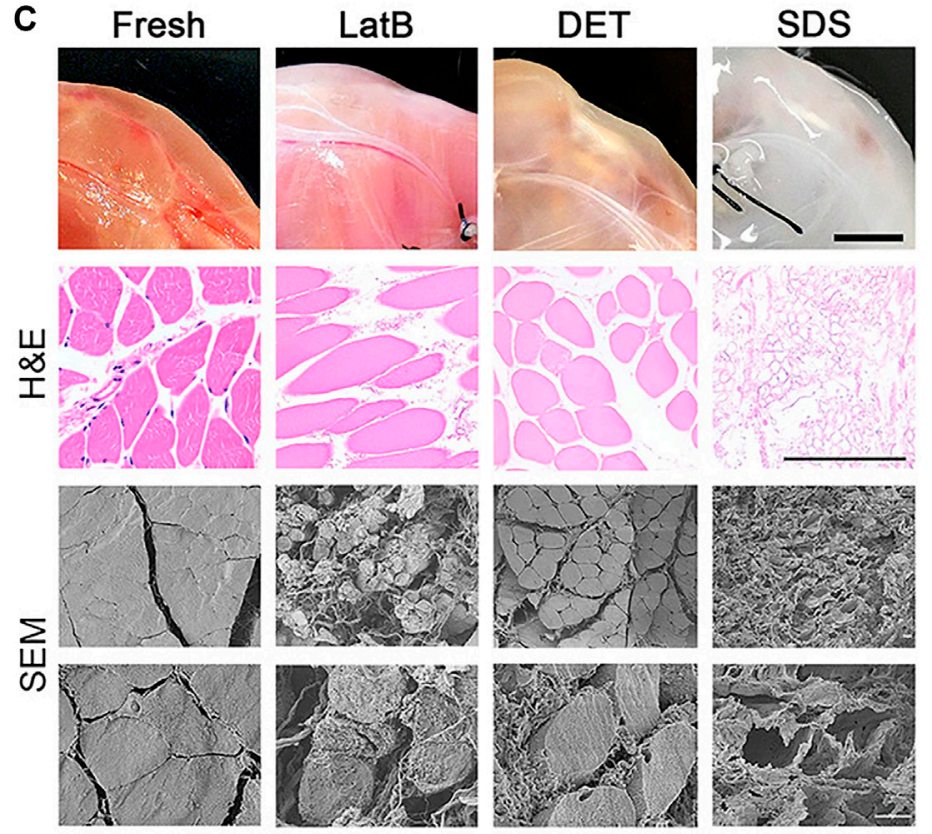

E

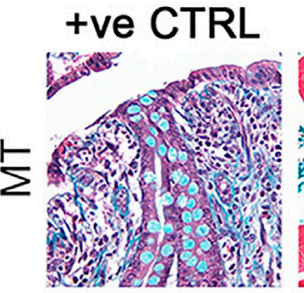

Fresh
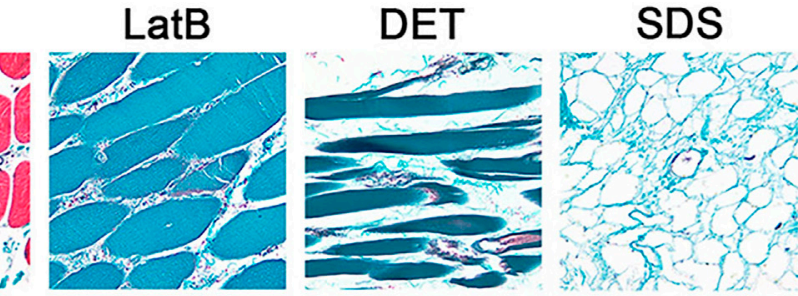

$\mathbf{F}$
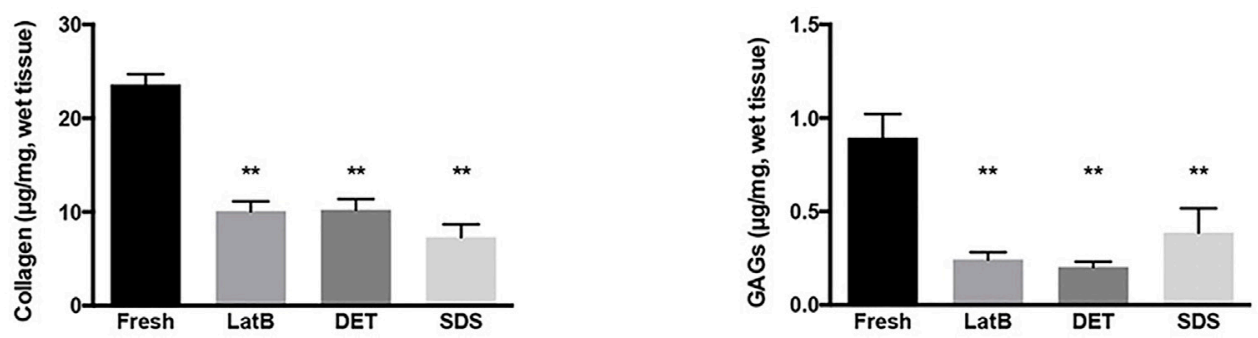

FIGURE 4 | Differences in decellularization protocols determine dECM properties in whole tissues (A) Schematic of tissue harvest from a rat hindlimb for whole muscle decellularization (B) A breakdown of three example decellularization protocols used in whole tissue decellularization (C) Final DNA content after whole tissue decellularization using three different decellularization protocols (D) Tissue morphology from top to bottom: Macroscopic tissue images, Hematoxylin and Eosin (H\&E) staining, and Scanning Election Microscope (SEM) images of whole tissues before (Fresh, first column) and after decellularization with LatB (second column), DET (third column), and SDS (fourth column) protocols (E) Massons Trichrome (MT) staining of whole tissue after decellularization (F) ECM content of collagen and GAGs remaining in decellularized whole tissues compared to fresh tissues. Figures A-F are adapted from "Decellularised skeletal muscles allow functional muscle regeneration by promoting host cell migration" by Urciuolo et al. (2018) licensed under CC BY 4.0. 
surface of the implant as well as moderate neo-muscle fiber presence up to $5 \mathrm{~mm}$ away from the defect. Neovascularization of the skeletal muscle dECM was also greater compared to the controls. Taken together, there is both utility and limitations of using a trypsin-based decellularization agent in which survival and proliferation of cells is supported in vitro but structural dysmorphism and loss of GAGs may impact in vivo applications.

\subsubsection{How Different Protocols Affect Skeletal Muscle dECM Composition and Cell Interaction - SDS}

A well strategized SDS treatment can be extremely effective at removing cellular debris, while still retaining ECM components. In an effort to restore normal muscle function following a severe muscle injury, Lee et al. decellularized minced rabbit skeletal muscles using 1\% SDS to create a dECM scaffold (Lee et al., 2020). A compositional analysis of the resulting ECM in the decellularized tissue showed the retention of approximately $50 \%$ collagen, $74 \%$ elastin, and $83 \%$ GAGs when compared to native skeletal muscle. When seeded with $\mathrm{C} 2 \mathrm{C} 12$ mouse myoblasts, the cellularized constructs maintained a $90 \%$ cell viability throughout the 7 days of culture. Alamar Blue assessment of metabolic activity of the cells in the muscle dECM demonstrated an increase in cell proliferation when compared to collagen controls. Additionally, greater in vitro myogenesis (myotube formation and maturation) was observed on the dECM scaffolds compared to controls. In a rabbit model of TA VML injury, treatment with the dECM scaffold was associated with a greater number of regenerated muscle fibers when compared to the collagen implant. Therefore, despite the reputation of SDS as a disruptive agent, dECM produced from an SDS protocol has been used for successful in situ muscle regeneration.

The decellularization of whole muscle tissues presents additional challenges due to the large volume of tissue that must interface with a decellularization agent to effectively remove cellular components. Protocols that aim to decellularize whole muscles typically include some form of SDS. To decellularize whole rat muscles, Kasukonis et al. employed a $1 \%$ SDS perfusion decellularization protocol (Kasukonis B. M. et al., 2016). ECM characterization of the decellularized tissue showed an approximately 90\% retention of both collagen and GAGs. In vitro, the AECM supported $\mathrm{C} 2 \mathrm{C} 12$ proliferation and in vivo implantation of the $\mathrm{dECM}$ scaffold with and without the addition of minced muscle autografts in a rat VML injury model resulted in reduced fibrosis when compared to the VML only control (Kasukonis B. et al., 2016; Kasukonis B. M. et al., 2016).

To characterize the effects of three different decellularization protocols, Urciuolo et al. employed a perfusion treatment for rat hind limbs using one of three agents: 1) LatB; 2) 4\% SDC; or 3) 0.25\% SDS (Urciuolo et al., 2018) (Figure 4A,B). Compared to native muscles, both $\mathrm{H} \& \mathrm{E}$ and SEM analyses displayed different histological characteristics as a function of decellularization agent (Figure 4C). Although the residual DNA content was statically lower than native tissues for all three treatments (Figure 4D), marked differences in global tissue morphology and myofiber structure was evident. Tissue architecture was extensively preserved in both the LatB and SDC treatment, whereas myofiber integrity was widely compromised in the SDS treatment (Figure 4E). Both the LatB and SDC protocols preserved about $50 \%$ of the native collagen content while the SDS protocol retained slightly less collagen at about $40 \%$ (Figure 4F). However, the same SDS treatment yielded tissues with a better retention of GAGs ( 45\%), compared to approximately a $25 \%$ retention for both the LatB and SDC treatments (Figure 4F). Angiogenic cytokine content was also quantified in the three dECMs and revealed a 30 and $25 \%$ retention of VEGF using the SDS and SDC protocols respectively, while the LatB protocol showed almost no residual VEGF when compared to native skeletal muscles. Additionally, SDS preserved the greatest amount of IGF-1 (60\% retainment) while both LatB and SDC correlated with about $33 \%$ compared to native tissues. To further test the regenerative potential of the decellularized tissues, each scaffold was transplanted into a murine extensor digitorum longus (EDL) VML injury model. All sites of implantation showed signs of tissue regeneration with partially restored muscle strength. Despite some differences in dECM composition, in vivo application of this material resulted in similar regenerative outcomes.

\subsubsection{How Different Protocols Affect Skeletal Muscle dECM Composition and Cell Interaction - LatB}

A non-proteolytic, non-detergent based, decellularization method was developed by Gillies et al. for whole skeletal muscle decellularization (Gillies et al., 2011). The protocol consisted of LatB, potassium chloride, potassium iodide, and DNase, applied to whole mice TA muscles. LatB functions by depolymerizing the actin and myosin filaments that are the structural supports of skeletal muscle, making cells more vulnerable to the effects of potassium chloride and potassium iodide salts which are hyper- and hypotonic solutions. Most notably, major ECM components were preserved. Amongst the ECM components, $60 \%$ of GAGs and $100 \%$ of collagen remained in the decellularized tissue. Moreover, when seeded with $\mathrm{C} 2 \mathrm{C} 12$ mouse myoblasts, the skeletal muscle dECM supported cell survival both on the surface and inside the scaffold.

Using this same LatB protocol, Fishman et al. decellularized the cricoarytenoid dorsalis muscles harvested from the larynx of adult rabbits (Fishman et al., 2012). The non-proteolytic, nondetergent protocol actively preserved several major ECM components, which corresponded with the retainment of about $75 \%$ collagen, $65 \%$ GAGs, preservation of elastin, and low presence of MHC classes I and II antigens. To test the biocompatibility and regenerative properties of the acellular tissue, the skeletal muscle dECM was transplanted into immunocompetent rats with a TA injury (Fishman et al., 2013). Compared to the control PCL scaffolds, the dECM scaffolds produced better cell survival and host integration.

Overall, the LatB decellularization approach pioneered by Gillies et al. is emerging as a viable alternative to the traditional SDS and trypsin treatments. Although a more mild protocol, LatB effectively preserves ECM components and may be an efficient approach for the decellularization of whole skeletal 
muscle decellularization without the need for perfusion bioreactors.

\section{BIOPHYSICAL PROPERTIES: TOPOGRAPHY}

The ECM is an elegant example of form supporting function. The ultrastructure of an ECM niche is dictated by the needs of the cells that it is designed to support. In the case of cardiac and skeletal muscle, this means that the tissue ECM is highly organized and anisotropic to enable fast and uniform transfer of contractile forces across the entire tissue. The topographical features of the ECM are present from the macrostructure down through the sub-cellular organization of fibrillar proteins. The spatial patterning of these structures provides a supportive niche that can direct cell organization, behavior, and function. Topographical patterning using dECM materials is generally performed using two different approaches: 1 ) use of the intact native matrix with original architecture; 2) use of solubilized matrix that is then printed into specific patterns to guide cell behavior.

\subsection{Cardiac dECM Topography}

The theme of alignment is pervasive throughout all levels of the cardiac tissue structure from the parallel orientation of the myocardial macrostructure to the sub-micron bands of the sarcomeres (Carson et al., 2016). Much of the structural alignment that is seen in cardiac tissue is primarily dictated by fibronectin and collagen fibers (Batalov et al., 2021), which have diameters ranging from 30 to $120 \mathrm{~nm}$ (Carson et al., 2016). Within these fibers are the integrin-binding domains that interact with cells to facilitate attachment and thereby are responsible for guiding cellular alignment. In fibronectin, the most common domain is the arginine-glycine-aspartate peptide (RGD) that facilitates binding through the $\alpha 5 \beta 1$ integrin complex (Bellis, 2011). Collagen also has RGD sequences, but these sites are largely inaccessible due to the conformation unless the collagen is cleaved by MMPs or denatured (Bellis, 2011). Other important binding players located on cell membranes are the $\alpha 1 \beta 1$ integrin complex, which primarily binds to collagen type IV, and the $\alpha 2 \beta 2$ integrin complex, which predominantly binds to collagen type I (Boraschi-Diaz et al., 2017). The accessibility of the integrin-binding domains following decellularization plays a decisive role in guiding cardiac cell binding and cytoskeletal organization. Therefore, the decellularization protocols aimed at generating $\mathrm{DECM}$ with specific topographical features, must prioritize the preservation of the ECM components that house these cell-binding domains.

\subsubsection{How Different Decellularization Protocols Affect Cardiac dECM Topography}

To enable the study of dECM topography, decellularization protocols must avoid disruption of key ECM proteins such as fibronectin and collagen fibers, which contain essential integrinmediated binding domains. Protocols that remove cells via cell swelling and rupture have been shown to physically disrupt the spatial environment, and repeated freeze-thaw cycles can be severely damaging to fibrillar proteins, leading to inconsistent fiber sizes (Behmer Hansen et al., 2021). Similarly, extended exposure to reagents such as trypsin, SDS, and Triton X-100 can disrupt glycoprotein microstructure which is important for cell adhesion and growth factor regulation (Wilgus, 2012; Gilpin and Yang, 2017). For example, Merna et al. found that hearts decellularized with a combination of trypsin and triton thoroughly removed DNA $(<1 \mathrm{ng} / \mathrm{mg}, \sim 90 \%$ removal $)$, but significantly disrupted the elastin architecture (Figure 3B) (Merna et al., 2013). In contrast, a triton-only regimen had less of an effect on elastin content and maintained crimped collagen fibers; however, the protocol resulted in only about $40 \%$ decellularization based on residual DNA content.

Fortunately, the most common cardiac decellularization approach of $1 \%$ SDS and $1 \%$ Triton X-100 is effective in the removal of cells and cellular debris without significant disruption to the ECM. (Ott et al., 2008; Robertson et al., 2014; Williams et al., 2014; Hochman-Mendez et al., 2020; Wang et al., 2020; Basara et al., 2021; Mousavi et al., 2021; Tsui et al., 2021). Using this classic decellularization approach, Hochman-Mendez et al. even confirmed that the wave-like topography of laminin in the cardiomyocyte basement membrane was preserved (Hochman-Mendez et al., 2020). However, the precise level of ECM feature preservation required for adequate cell binding, growth, and patterning still remains to be extensively characterized.

\subsubsection{How Cardiac dECM Topography Affects Cell Behavior In Vitro}

A significant body of work has been done to study native topography and to characterize the drivers of cardiomyocyte alignment. Micropatterning, nanofiber electrospun scaffolds, flexible posts, and electrical fields are just some of the methods used to guide alignment in vitro (Au et al., 2007; Carson et al., 2016; Leonard et al., 2018; Suh et al., 2020; Batalov et al., 2021). While it is well understood that the orientation and elongation of cardiac cells is essential for maturation and proper contractile function, the field has yet to fully elucidate the underlying biophysical, mechanical, and molecular mechanisms that facilitate alignment.

To better understand these complex relationships, Schwan et al. developed an engineered heart tissue (EHT) system from laser cut, decellularized porcine myocardial sheets (Schwan et al., 2016). A major insight from this work was that local matrix cues from the EHT were more influential in guiding cellular alignment than macroscopic cues such as applied load or stiffness, which are historically potent modulators of alignment in isotropic gels (Schwan et al., 2016). When the EHT was recellularized with neonatal rat ventricular myocytes, human embryonic stem cell derived cardiomyocytes, or human induced pluripotent stem cell derived cardiomyocytes (iPSC-CMs), the resulting construct displayed spontaneous beating, cellular alignment, organized sarcomeres, and gap junctions. They found that the mechanical properties, such as peak twitch stress, were dictated by the orientation of the fibers and could be used to recapitulate the contractile anisotropy displayed by native tissues. 


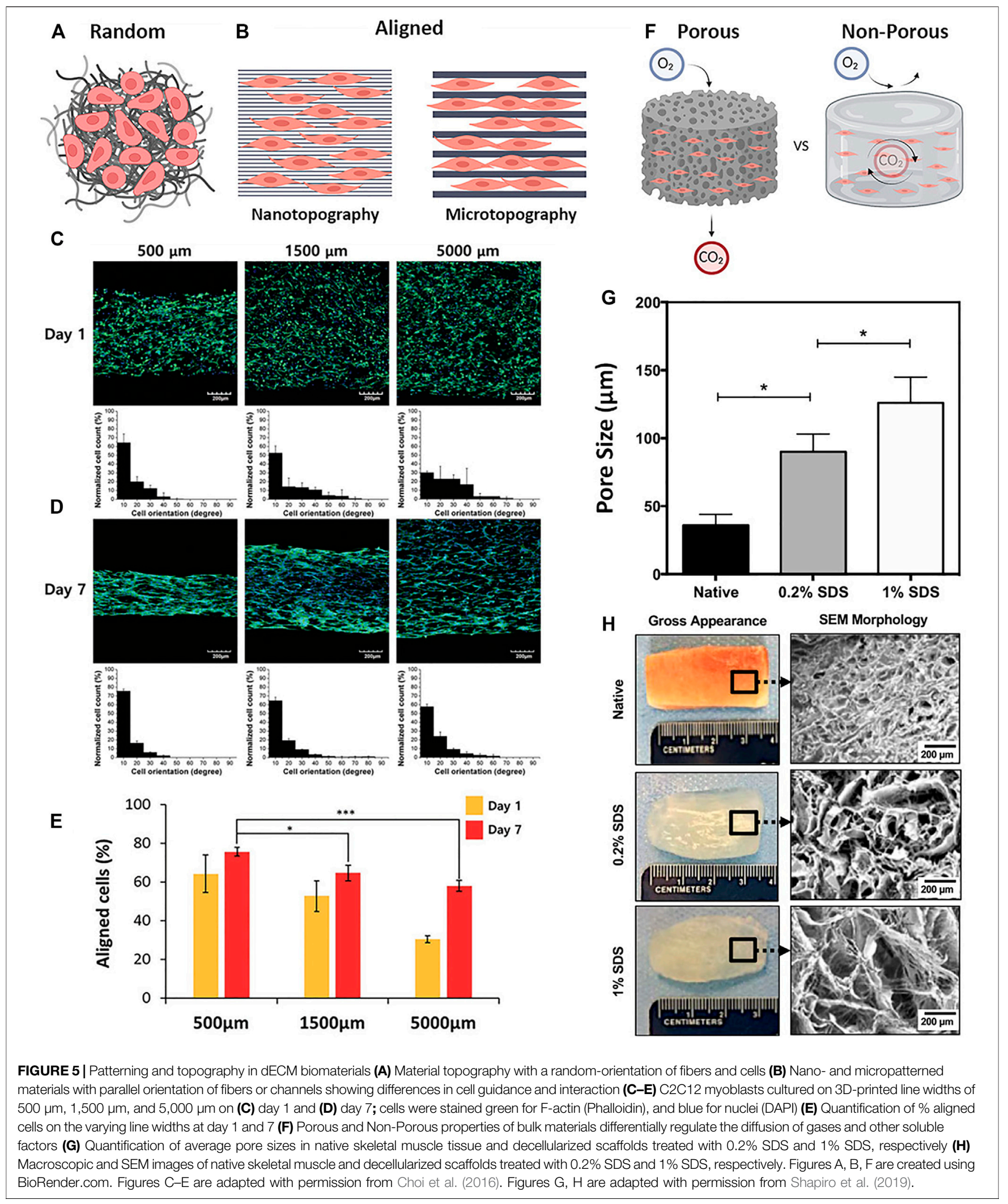


Moreover, when they compared the EHT to another anisotropic scaffold, electrospun gelatin, they found that the EHT had a stronger peak stress, suggesting that the $\mathrm{AECM}$ possess a diverse multitude of biomechanical factors that similarly patterned synthetic materials cannot recapitulate.

\subsubsection{How Cardiac dECM Topography Affects Cell Regeneration In Vivo}

The vast majority of in vivo studies that use cardiac dECM, do so by using the material in a solubilized form. While topography and patterning of AECM in vitro may have provided evidence of guiding cellular and biomechanical outcomes, the story in vivo is different. Cardiac dECM injectable therapeutics have had promising results (Singelyn et al., 2012; Wang et al., 2019; Wang et al., 2020). However, there are a few studies that showed the benefit of using dECM with preserved topography as a tool for enhancing cell recruitment or delivery in small animal injury models. Sarig et al. implanted decellularized porcine cardiac patches into rats following induced MI and observed recruitment of native macrophages and cardiomyocyte progenitor cells (CPCs) (Sarig et al., 2016). Recruited CPCs organized into fiber-like clusters with partial striation and positive staining for gap junction marker Connexin43. Sarig et al. concluded that their dECM patch, without recellularization, improved contractility, ejection fraction, and cardiac remodeling following MI (Sarig et al., 2016).

Like Sarig et al., Wang, Q. et al. used intact rat decellularized ECM patches for treatment post MI in a rat model, but also directly compared acellular AECM patches to dECM patches cultured with human iPSC-CMs and CD90 $0^{+}$nonmyocytes (Wang et al., 2016). They found that recellularized patches significantly improved ejection fraction and vascular density, while decreasing infarct size in comparison to acellular dECM patches. However, their recellularization did not produce adequate cellular alignment or cardiomyocyte maturation and they did not study recruitment of host cells. Taken together, in vivo application of cardiac dECM is largely driven by modulation of the regenerative niche by the ECM components and, to a much lesser extent, by any specific surface patterning or topographical features.

\subsection{Skeletal Muscle dECM Topography}

Many studies that look at the topographical contribution of decellularized skeletal muscle aim to utilize and/or mimic the naturally aligned pattern of the ECM to guide myogenic cell differentiation. Similar to cardiac muscle, skeletal muscle is highly oriented along a common axis and is composed of functional myofiber units that are organized in parallel to maximize force contraction. Skeletal muscle is anisotropic and is made up of tightly bundled, aligned structures of densely-packed myofibers (Jana et al., 2016). In the field of skeletal muscle regeneration, differentiation of new myofibers along a uniform direction is a key feature of a successful biomimetic material and supportive niche. Furthermore, it has been widely demonstrated that topographical patterning of cells has a significant impact on morphology, behavior, and function (Nakayama et al., 2018; Nakayama et al., 2019). There are several reoccurring themes in the area of topographical patterning and skeletal muscle dECM that include the contribution of alignment/ anisotropy, scale (micro versus nano), and porosity (Figure 5).

\subsubsection{How Skeletal Muscle dECM Topography Affects Cell Behavior- Alignment}

The alignment-mediated cellular response is a key player in myogenesis and the development of functional myotubes and physiologically mimetic myofibers (Ostrovidov et al., 2014). Substrates with either aligned or randomly-patterned topography are often used to assess or enhance contact-driven myogenic fusion (Figure 5A). One approach that utilizes skeletal muscle dECM with controlled topographical patterning was demonstrated by Kim et al. using 3D bioprinting methods to produce a cell-laden, dECM-based structure with unique topographical cues (Kim et al., 2020). To test the effect of uniaxial topographical patterning, $\mathrm{C} 2 \mathrm{C} 12$ mouse myoblasts were seeded onto either aligned or non-patterned dECM scaffolds and were cultured for 21 days. Significantly greater myoblast alignment, myotube formation, and myogenic gene expression (MyoD1, MYH2, Myog) was observed in the aligned patterned $\mathrm{dECM}$ scaffolds when compared with the non-patterned controls. In another alignment-focused study, through the use of elastomeric chips made from polydimethylsiloxane (PDMS), the kinetics of dECM fibrillogenesis was controlled to fabricate both aligned and non-patterned dECM hydrogel scaffolds loaded with induced skeletal muscle progenitor cells (iMPCs) (Jin et al., 2021a). iMPCloaded aligned dECM hydrogel scaffolds showed increased cell alignment and expression of myogenic markers Mrf5, MyoD1, and Myog at day 10 of in vitro cell culture. In vivo implantation of both aligned and non-patterned iMPC-loaded 3D constructs in a VML quadriceps femoris mouse model demonstrated a significant reduction of fibrosis as well as greater de novo muscle regeneration in the aligned iMPC-loaded hydrogel scaffold compared to the non-patterned control. These combined studies highlight the ability of physical cell alignment to enhance myogenesis in vitro and muscle regeneration in vivo.

Hybrid dECM bioinks are another approach to guiding alignment-mediated muscle regeneration. Lee et al. created aligned and randomly-oriented bioprinted skeletal muscle constructs using photo-crosslinkable dECM bioink together with poly(vinyl alcohol) (PVA) to modulate topography. The self-aligned printed muscle constructs improved myogenic differentiation in vitro evidenced by the expression of mature myogenic markers (MYH4 and MYH2) and exhibited rapid restoration of muscle function in vivo in a rat tibialis anterior VML model (Lee et al., 2021). The aligned constructs showed increased myofiber formation, reduced fibrotic tissue area, significant $\mathrm{MHC}^{+}$expression, and greater tetanic force production. Together, these studies underscore the modulatory role of $\mathrm{dECM}$ alignment in guiding myogenesis.

\subsubsection{How Skeletal Muscle dECM Topography Affects Cell Behavior- Scale}

Topography can be modulated on the micro- or nano-scale to guide cell behavior and myogenesis; however, it is a highly contested topic as to which topographical scale is most effective at achieving the optimal cell response (Skoog et al., 
2018) (Figure 5B). Because of the increasing accessibility of technologies such as 3D bioprinting, electrospinning, soft- and photolithography, patterning using lower resolution microscale topographies are more widely used compared to higher resolution nanoscale topographies (Chia and Wu, 2015). For example, Choi et al. fabricated micro-scale cell-laden dECM muscle constructs using $3 \mathrm{D}$ printing of $\mathrm{dECM}$ with line widths that ranged between 300 and $1,000 \mu \mathrm{m}$. The micropatterned $3 \mathrm{D}$ printed constructs demonstrated high cell viability and supported the formation of densely packed aligned-myotubes compared to non-patterned controls. Furthermore, to assess therapeutic efficacy, the $3 \mathrm{D}$ micropatterned muscle constructs were implanted into the defect site of a rat tibialis anterior VML injury and displayed de novo muscle regeneration and minimal fibrosis when compared to the non-patterned controls (Choi et al., 2019).

Studies have also been done using dECM with different pattern scales to determine the optimal fiber size for myogenesis in vitro. Using $3 \mathrm{D}$ bioprinting, Choi et al. constructed C2C12-laden scaffolds with fibers that ranged between 500 and 5,000 $\mu \mathrm{m}$ (Choi et al., 2016) (Figure 5C,D). It was found that the greatest cellular alignment, elongation, and mechanical strength was seen by cells cultured on scaffolds with the higher resolution range of $500 \mu \mathrm{m}$ patterning (Figure 5E). Evidence that smaller topographies may lead to enhanced myogenesis was demonstrated by this same group using deep $\mathrm{X}$-ray lithography to fabricate sinusoidal microscale patterns of dECM in the range of $20-80 \mu \mathrm{m}$ (Choi et al., 2018). These wavy dECM surfaces induced myoblast alignment and enhanced myotube formation and differentiation.

Nano-scale ECM topographies have been shown to play a potent role in guiding cell morphology, phenotype, differentiation, and function (Nakayama et al., 2015; Nakayama et al., 2016; Nakayama et al., 2018; Nakayama et al., 2019; Patel et al., 2019; Patel et al., 2020; Jin et al., 2021a). In a study by Patel et al., dECM and polycaprolactone (PCL) were electrospun together to mimic the topographical architecture of native muscle with a fiber diameter range of 500-2000 nm (Patel et al., 2019). The hybrid scaffolds were capable of supporting myogenic cell growth and the secretion of myokine growth factors. The nanofiber scaffold promoted in vivo muscle regeneration in a murine model of gastrocnemiussoleus VML with increased myofiber $\left(\mathrm{MHC}^{+}\right)$regeneration and elevated activity of anti-inflammatory M2 macrophage (arginase $^{+}$) compared to the control groups (Patel et al., 2020). Similarly, nano-scale topographies were used to guide myogenesis using elastomeric PDMS chips together with iMPCs to support mature myotubes in vitro and de novo muscle regeneration with induced functional restoration of injured quadriceps femoris muscles in a VML mouse model (Jin et al., 2021a).

Both micro- and nano-topographies have been shown to guide myogenesis and functional muscle regeneration in vitro and in vivo and the optimal topographical scale is dependent on several factors including the desired cellular interactions, type of cells, and substrate properties.

\subsubsection{How Skeletal Muscle dECM Topography Affects Cell Behavior- Porosity}

The porosity of a biomaterial determines the rate of transportation of gases, removal of waste products, and diffusion of macromolecular proteins from the surrounding environment into the bulk space of the matrix (Choi et al., 2019; Jin et al., 2021a) (Figure 5F). Shapiro et al. demonstrated that different concentrations of SDS effect the pore size of the resulting $\mathrm{dECM}$, such that increasing concentrations of SDS produced tissues with greater pore sizes (Shapiro et al., 2019) (Figures 5G,H). The larger pore sizes better supported cell infiltration and allowed for the controlled release of IGF-1 to enhance in situ muscle regeneration. In a study done by Jin et al., four different types of dECM-PCL substrates were thermally drawn into sheets or fibers following a salt leaching method to incorporate porosity (Jin et al., 2021b). The four types of substrates include non-porous sheets, porous sheets, nonporous fibers, and porous fibers. Culture of iMPCs on the four different substrates resulted greater expression of myogenic genes (MyoD1, Mrf5, Myog, ITGB1, ITGA7, and CDH2) within the porous group when compared to the non-porous group. Others have demonstrated better cell viability when using porous $\mathrm{dECM}$ scaffolds compared to non-porous hydrogels (Choi et al., 2019), implicating possible cell hypoxia when scaffolds are not sufficiently porous.

Combinatorial effects of alignment plus porosity have also been associated with improved cellular outcomes. In a comparison of aligned (pore size of $3.39 \mu \mathrm{m}$ ) versus randomlyoriented (pore size of $2.58 \mu \mathrm{m}$ ) muscle constructs, greater cell viability if iMPCs was seen on the aligned scaffolds, which contained the larger pores, compared to the randomlypatterned scaffolds, which contained the comparatively smaller pore size (Jin et al., 2021a). Together, these studies underscore the significance and modulatory role of porosity in the use of skeletal muscle dECM to fabricate regenerative biomaterials; excessively high porosity will lead to lower structural integrity (Jakus et al., 2018) and a lack of porosity will potentiate hypoxia and cell death (Jin et al., 2021a).

\section{BIOPHYSICAL PROPERTIES: MECHANICAL PROPERTIES}

Cell biomechanics are constantly at play in the regulation of tissue homeostasis and response to injury. In native tissues, cells are naturally exposed to physical forces such as compressive loading, tensile strain, shear, and electrical stimulation (Rando and Ambrosio, 2018). These dynamic mechanical cues transduce signals from the surrounding extracellular environment through the cell membrane and into the cell's nucleus to influence the transcriptional programs that drive morphogenesis. By modulating the process of mechanotransduction, ECM-derived biomaterials can guide cells towards tissue remodeling, regeneration, and ultimately repair following injury. 


\subsection{Cardiac dECM Mechanical Properties}

Disease, injury, and aging cause irreversible remodeling to cardiac ECM leading to fibrosis and a subsequent increase in stiffness, decreased contractility, and eventual heart failure. Due to the dynamic loading and contractile demands of the heart, an effective engineered therapeutic must support and recapitulate these functional mechanical properties. While cardiac dECM has been used to enhance the mechanical integrity of engineered cardiac tissues, the exact contribution of specific dECM biomechanical properties such as architecture, elasticity, and stiffness to the overall outcomes is not well-established (Silva et al., 2016).

\subsubsection{How Different Decellularization Protocols Affect Cardiac dECM Mechanical Properties}

The exact relationship between specific mechanical properties and the decellularization protocols used to generate these cardiac dECMs is not well-characterized. While there is a consensus that restoration of functional cardiac mechanics is a key benchmark of a successful regenerative technology, there is a marked lack of published studies that characterize the dECM mechanics (Behmer Hansen et al., 2021). However, some broad correlations can be made between some decellularization approaches and the resulting effects on cardiac dECM elasticity and strength. Decellularization protocols that utilize SDS and Triton X-100 for long periods of time risk damaging collagen and elastin fibers by decreasing fiber thickness and losing ultrastructure (Merna et al., 2013; Gilpin and Yang, 2017; Lee et al., 2017; Behmer Hansen et al., 2021). These alterations to ECM glycoproteins can have detrimental effects as they play a role in maintaining cardiac elasticity and tensile strength (Behmer Hansen et al., 2021). Merna et al. measured compressive modulus following various whole heart perfusion decellularization protocols. They found decellularization with triton increased the compressive modulus by $150 \%$ in comparison to the native heart while a trypsin plus triton regimen decreased the compressive modulus by $<20 \%$ (Merna et al., 2013). Careful preservation of dECM mechanical properties and elasticity is especially challenging for perfusion systems which risk overinflating the heart and causing damage to the elastin fibers. Therefore, methods have been developed that optimize perfusion and gravitational forces to minimize mechanical strain during decellularization. Lee et al. found that inverting the heart at a $-45^{\circ}$ angle, improved perfusion efficiency and also improved retention of ECM proteins and heart shape (Lee et al., 2017).

\subsubsection{How Cardiac dECM Mechanical Properties Affect Cell Behavior}

Decellularized cardiac ECM provides mechanical cues that have the potential to improve cell attachment, differentiation, and maturation (Lu et al., 2013; Williams et al., 2014; Fong et al., 2016; Sarig et al., 2016; Das et al., 2019; KC et al., 2019; HochmanMendez et al., 2020; Mesquita et al., 2021). Specifically, cardiac dECM substrate stiffness can guide cell migration, proliferation, differentiation, and maturation (Merna et al., 2013; Perea-Gil et al., 2018). It has been shown that cardiomyocytes prefer softer substrates; when cultured on poly(ethylene glycol) and fibrinogen (PEGylated fibrinogen) hydrogels, an inverse correlation was found between material stiffness and the magnitude of cardiomyocyte contraction (Shapira-Schweitzer and Seliktar, 2007). As a therapeutic, dECM can provide mechanical support to the injured myocardium and must closely match the native contractile properties. If the $\mathrm{dECM}$ does not reflect native stiffness or the recellularized $\mathrm{AECM}$ construct contains immature cells, arrhythmias and a cascade of negative immune responses will occur leading to further scarring (Zhang et al., 2018). Therefore, dECM scaffolds must recapitulate the stiffness and mechanical properties of native myocardium as well as support cardiomyocyte contraction and maturation.

\subsection{Skeletal Muscle dECM Mechanical Properties}

Much like cardiac dECM, the influence of skeletal muscle dECM mechanical properties on myogenesis and muscle regeneration is not well-characterized. The biophysical dECM properties such as biochemical composition and topographical patterning are often the primary targets for modulation of cell behavior and less attention is given to controlling cellular interactions via classical tissue biomechanics. However, replicating the mechanical properties of skeletal muscle are a crucial component in the design of engineered skeletal muscle and regeneration in vivo (Lacraz et al., 2015).

The compressive stiffness of skeletal muscle dECM is heavily influenced by the decellularization reagents. In a study by Reyna et al. that compared three different decellularization methods, it was found that the SDS/Triton $\mathrm{X}$ and Triton X-only treated tissues had similar stiffnesses to the collagen control, while a LatB treatment produced the least stiff tissue across all groups (Reyna et al., 2020). While this specific study did not examine the downstream effects of stiffness on cellular interactions, two other studies found that the specific dECM that most closely resembled the stiffness of native muscle, promoted the greatest myogenesis in vitro and muscle regeneration in vivo (Choi et al., 2016; Jin et al., 2021b). To mimic the native structure of muscle, Choi et al. 3D printed muscle scaffolds using dECM bioinks (Choi et al., 2016). The dECM printed muscle scaffold exhibited a stiffness $(12 \pm 3 \mathrm{kPa})$ similar to that of native muscle $(\approx 12 \mathrm{kPa})$ and also supported myoblast proliferation, myotube formation, and myogenic differentiation in vitro.

Mechanical variance is unavoidably introduced when dECM is fabricated into scaffolds with varying physical properties, and likely plays a contributing role in guiding subsequent cellular interactions. Jin et al. fabricated two types of muscle constructs by thermal drawing; a porous/ fibrous scaffold $(12.4 \pm 3.5 \mathrm{kPa})$, and a porous/sheet-like scaffold $(29.0 \pm 3.8 \mathrm{kPa})$ (Jin et al., 2021b). The porous/ fibrous scaffold had a stiffness that was most similar to native muscle $(11.5 \pm 1.3 \mathrm{kPa})$ and outperformed all other groups in myogenesis both in vitro and in vivo. Similar to cardiac dECM, the regenerative potential of skeletal muscle $\mathrm{dECM}$ is optimized when the scaffold's mechanical properties most closely resemble that of the native tissue. 


\section{EMERGING RESEARCH}

The complementary fields of cardiac and skeletal muscle dECM research will continue to evolve and pioneer novel methods and tools for regenerative medicine. There are some very recent studies that stand apart in novelty and provide valuable insights and first steps that have the potential to take the field in a new direction. Herein, select studies are described that approach DECM research from an unexpected direction. While many of these studies were published within the past few years, they describe a dECM application that is a drastic departure from where the majority of the field currently resides.

\subsection{Emerging Research in Cardiac dECM}

The initial translational goal for cardiac $\mathrm{dECM}$ research was to use whole decellularized hearts as a therapeutic alternative for waitlisted organ transplant candidates. While this approach has yet to meet the clinical milestones necessary for a patient-applied treatment, cardiac dECM is nevertheless a versatile and powerful tool used in cardiomyocyte differentiation, maturation, and proliferation (Hochman-Mendez et al., 2020; Mesquita et al., 2021). It has also shown great promise as a therapeutic for the treatment of myocardial infarction, either in the form of a solubilized injectable gel or as an intact cardiac patch. (Sarig et al., 2016; Wang et al., 2016; Wang et al., 2019; Wang et al., 2020). However, despite the many studies demonstrating the utility of dECM for cardiac applications, there remains a gap in knowledge and bottlenecks in clinical translation.

To tackle the ongoing challenge of obtaining a renewable and robust supply of human cardiac $\mathrm{dECM}$, one group has looked towards the use of cardiac organoids as a cultured source for dECM. Chiang et al. used organoids derived from human umbilical cord blood mesenchymal stem cells to lay down a structural protein niche that was then decellularized to provide a dECM scaffold (Chiang et al., 2021). The resulting dECM was shown to possess both essential microarchitecture and functional bioactivity (Chiang et al., 2021). This approach can be easily scaled up to produce large quantities of tissuespecific human ECM under reproducible and controlled laboratory conditions. Through the use of organoid-derived dECM, several major bottlenecks are circumvented by moving away from highly variable animal-derived products towards an approach that could be more easily standardized in a higher throughput setting.

Another approach for AECM cardiac tissue engineering that circumvents the need for healthy cardiac tissue as source material, is the use of other organs such as placenta or small intestine submucosa (SIS) for cardiac applications. Jiang et al. decellularized rat placentas which are highly vascularized, rich in ECM, and more readily available than hearts (Jiang et al., 2021). They recellularized the placenta with hiPSC-CMs and observed spontaneous contraction at a rate of $40-100 \mathrm{bpm}$. The hiPSC-CMs were also responsive to isoprenaline and had synchronized electromechanical propagation with external electrical stimulation. Additionally, the decellularized placenta significantly upregulated mRNA expression of genes related to cardiomyocyte structure, maturation, and conduction compared to cells culture on Matrigel coated tissue culture plastic. To test the therapeutic efficacy of their bioengineered cardiac patch (BCP), a rat myocardial infarction model was used. BCPs significantly improved left ventricular function, decreased infarct size, and increased cell retention compared to decellularized placenta or hiPSC-CMs alone after 4 weeks (Jiang et al., 2021).

The general concept of repurposing non-cardiac $\mathrm{dECM}$ for cardiac applications has also garnered significant interest and excitement with the emerging field of plant decellularization. Although decellularized vegetal scaffolds do not contain identical ECM components to decellularized cardiac tissues, their use has increased in popularity in recent years due to their innate networks for fluid transportation that resembles the human tissue vasculature. Additionally, plant tissue possesses similar mechanical properties, are highly accessible at a low cost, and non-immunogenic in nature (Harris et al., 2021). Plant tissue is primarily composed of cellulose, a well-studied, biodegradable compound that is widely used in a variety of clinical applications including wound dressing and drug delivery (Harris et al., 2021). Decellularized vegetal scaffolds are often coated with fibronectin, collagen, or poly-L-lysine (PLL) to promote cellular attachment and tune mechanical properties (Robbins et al., 2020; Harris et al., 2021). For cardiac tissue engineering, decellularized spinach (spinacia oleracea) and tomato (solanum lycopersicum) leaves have been identified as the ideal source material because their mechanical properties are in the range of human cardiac tissue (Gershlak et al., 2017; Robbins et al., 2020; Harris et al., 2021). Gershlak et al. decellularized spinach leaves, coated with fibronectin, and recellularized the vascular component with human umbilical vein endothelial cells (HUVECs) and the surface of the leaves with a combination of human mesenchymal stem cells (hMSCs) and hiPSC-CMs. The vasculature remained patent and perfusable and all cell types adhered and matured over the course of the 21 days study. The hiPSC-CMs began to spontaneously contact 5 days after seeding, exhibiting a $1 \%$ contractile strain and a contractile rate of $0.8 \mathrm{~Hz}$ (Gershlak et al., 2017). More recently, the same group recorded $3.94 \pm 1.20 \%$ contractile strain which they hypothesized was due to their updated decellularization protocol which uses 1\% SDS instead of $10 \%$ SDS (Robbins et al., 2020). While these results are promising, the contractile strain is still much smaller than the of adult myocardium (15.9-22.1\%) (Yingchoncharoen et al., 2013). Therefore, significant work is still needed to meet the clinical milestones necessary for this cardiac patch to become a patientapplied treatment. Nonetheless, the use of plant-derived dECM for regenerative cardiac applications is an exciting new direction and may catalyze a paradigm shift and permenant new direction for cardiac decellularization.

\subsection{Emerging Research in Skeletal Muscle dECM}

The gold standard technology in skeletal muscle decellularization is experiencing a gradual shift away from the use of whole acellular tissue scaffolds towards more controlled 3D bioprinted approaches. Skeletal muscle dECM is now often solubilized into a bioink for extrusion printing, which allows 
for the construction of complex geometries and patterns that can be printed in multiple layers to support different cell types and deep vascular networks. A major advantage of muscle dECM printing is the ability to mass produce large quantities of bioactive materials, which has the potential to increase accessibility and thereby pave a smoother road towards clinical adoption as a therapeutic for muscle regeneration. However, despite these many advancements in skeletal muscle $\mathrm{dECM} 3 \mathrm{D}$-printing, the ability to commercialize $\mathrm{dECM}$ using strictly bio-printing technology has yet to be fully realized (Dzobo et al., 2019). Many of the same bottlenecks originally associated with whole tissue decellularization, such as the yield of dECM, tissue supply, and cost, are carried over into $3 \mathrm{D}$ bioprinting approaches. These factors all still need to be evaluated before large-scale commercialization is possible. Therefore, similar to cardiac tissues, alternative sources of $\mathrm{dECM}$ materials have been a recent focus for skeletal muscle regeneration.

As an alternative to animal-derived proteins, some select plants are emerging as materials for engineering aligned muscle fibers. Monocotyledon plants, such as green onions, have a highly structured parallel architecture made up of cellulose. Decellularized monocotyledon plants possess anisotopy similar to striated human muscle tissue and were show to guide myogenesis through these topographical cues (Cheng et al., 2020). A wide variety of plants were decellularized using a basic protocol of $1 \%$ SDS for a 3 weeks duration. Out of the fruits and vegetables that were decellularized in the study, the monocotyledon plants such as asparagus, green onions, leeks, and celery all exhibited good anisotropic and aligned scaffold structures. This unidirectional structure in green onion plants, comprised of grooves that are about $20 \mu \mathrm{m}$ wide and $10 \mu \mathrm{m}$ deep, served as natural topographical templates for myogenesis (Cheng et al., 2020). Specifically, decellularized plants scaffolds seeded with human skeletal muscle cells (hMSCs) and C2C12 myoblasts induced a higher level of anisotropic organization of both cell types when compared to glass coverslip controls. Furthermore, the plant scaffolds demonstrated greater myogenesis in the form of myotube formation compared to controls. In the cardiac study by Gershlak et al., which also utilized dicotyledon plants (decellularized spinach leaves), it was shown that a wide range of cell types including endothelial cells and mesenchymal stem cells, are supported by these decellularized plant materials (Gershlak et al., 2017). Given the diverse assortment of decellularizable plant structures, this approach reduces the potential production cost, impact on the environment, and offers a vegan-friendly foundation for bringing this technology to mass production.

Engineering plant-based solutions could also solve a major problem in the meat production industry. About $60 \%$ of global greenhouse gas emissions can be traced back to the production of animal-based foods (Xu et al., 2021). Bioartificial lab-grown meat is an emerging area in the biotechnology sector and has the potential to provide edible meat alternatives to large sectors of the global population. There are currently over 70 cultured meat startup companies and who collectively raised $\$ 366$ million last year (Byrne and Murray, 2021). These companies produce cell-based meat that mimics beef, poultry, pork, and seafood and many base their products on derivatives of $\mathrm{AECM}$. In a specific study by Jones et al., decellularized spinach leaves were used as a matrix for culturing bovine satellite cells as they were developed into edible "meat" (Jones et al., 2021). The decellularization of spinach leaves utilized a $1 \%$ SDS protocol, and resulted in a dECM structure filled with a deep hollow vascular network suitable for cellular infiltration. Approximately $25 \%$ of the bovine satellite cells stained positive for myosin heavy-chain expression and showed good cytoskeletal alignment (average kappa value of $0.71 \pm 0.1$ ) supportive of anisotropic myogenesis. While the field of cultured meats is still relatively young, if successful, this industry has the potential to make a massive impact on the supply chain of food worldwide.

\section{COMMENTARY ON FUTURE DIRECTIONS FOR CARDIAC AND SKELETAL MUSCLE dECM}

Although the use of AECM in tissue engineering has led to many paradigm-shifting insights, there is still much work to be done before it can become standard clinical practice. There needs to be better methods for standardization of decellularization protocols and AECM characterization following decellularization. Many of the published protocols do not specify durations and often assess decellularization visually based on non-quantitative color-based metrics. To overcome batch-to-batch variations, decellularization protocols should be followed by characterization of both the biochemical and mechanical properties of the AECM using such tools as liquid chromatography-mass spectrometry, atomic force microscopy, and electron microscopy. It is crucial to retain the structure and bioactive components of the AECM and it has been shown that overexposure to many of the decellularization agents cause irreversible damage. Conversely, incomplete decellularization results in unwanted immune responses and limits recellularization. To date, there is no universal decellularization protocol as there are many complex factors that influence how a tissue will decellularize. Oftentimes, the selected protocol is a true compromise built on the sacrifice of some biophysical properties in favor of others. As our understanding of the underlying mechanisms driving cell-dECM interactions are uncovered, the fields of cardiac and skeletal muscle decellularization will evolve and refine to increase in translational relevance and expand in impact on human health.

\section{AUTHOR CONTRIBUTIONS}

$\mathrm{KN}, \mathrm{YT}$, and HH. designed, wrote, and edited the manuscript. YT and $\mathrm{HH}$ contributed equally.

\section{FUNDING}

This work was supported by grants to KN through the National Institutes of Health (National Heart, Lung and Blood Institute R00HL136701); Alliance for Regenerative Rehabilitation Research and Training (CNVA00048860); the Oregon Health and Science University Foundation (Collins Medical Trust); and 
MTF Biologics. This work was also supported by fellowships to $\mathrm{HH}$ through the Oregon Health and Science University Strain Fellowship; the National Institutes of Health (National Institute

\section{REFERENCES}

Akhyari, P., Aubin, H., Gwanmesia, P., Barth, M., Hoffmann, S., Huelsmann, J., et al. (2011). The Quest for an Optimized Protocol for Whole-Heart Decellularization: a Comparison of Three Popular and a Novel Decellularization Technique and Their Diverse Effects on Crucial Extracellular Matrix Qualities. Tissue Eng. C: Methods 17 (9), 915-926. doi:10.1089/ten.TEC.2011.0210

$\mathrm{Au}$, H. T. H., Cheng, I., Chowdhury, M. F., and Radisic, M. (2007). Interactive Effects of Surface Topography and Pulsatile Electrical Field Stimulation on Orientation and Elongation of Fibroblasts and Cardiomyocytes. Biomaterials 28 (29), 4277-4293. doi:10.1016/j.biomaterials.2007.06.001

Basara, G., Ozcebe, S. G., Ellis, B. W., and Zorlutuna, P. (2021). Tunable Human Myocardium Derived Decellularized Extracellular Matrix for 3D Bioprinting and Cardiac Tissue Engineering. Gels 7 (2), 70. doi:10.3390/gels7020070

Batalov, I., Jallerat, Q., Kim, S., Bliley, J., and Feinberg, A. W. (2021). Engineering Aligned Human Cardiac Muscle Using Developmentally Inspired Fibronectin Micropatterns. Sci. Rep. 11 (1), 11502. doi:10.1038/s41598-021-87550-y

Behmer Hansen, R. A., Wang, X., Kaw, G., Pierre, V., and Senyo, S. E. (2021). Accounting for Material Changes in Decellularized Tissue with Underutilized Methodologies. Biomed. Res. Int. 2021, 1-15. doi:10.1155/2021/6696295

Bejleri, D., Streeter, B. W., Nachlas, A. L. Y., Brown, M. E., Gaetani, R., Christman, K. L., et al. (2018). A Bioprinted Cardiac Patch Composed of Cardiac-Specific Extracellular Matrix and Progenitor Cells for Heart Repair. Adv. Healthc. Mater. 7 (23), 1800672. doi:10.1002/adhm.201800672

Bellis, S. L. (2011). Advantages of RGD Peptides for Directing Cell Association with Biomaterials. Biomaterials 32 (18), 4205-4210. doi:10.1016/j.biomaterials.2011. 02.029

Bloom, D. E., Cafiero, E. T., Jané-Llopis, E., Abrahams-Gessel, S., Bloom, L. R., Fathima, S., et al. (2011). The Global Economic Burden of Noncommunicable Diseases. Geneva: World Economic Forum.

Boraschi-Diaz, I., Wang, J., Mort, J. S., and Komarova, S. V. (2017). Collagen Type I as a Ligand for Receptor-Mediated Signaling. Front. Phys. 5 (12). doi:10.3389/ fphy.2017.00012

Byrne, B., and Murray, S. (2021). 2020 State of the Industry Report: Cultivated Meat. Washington, DC: Good Food Institute.

Carson, D., Hnilova, M., Yang, X., Nemeth, C. L., Tsui, J. H., Smith, A. S. T., et al. (2016). Nanotopography-Induced Structural Anisotropy and Sarcomere Development in Human Cardiomyocytes Derived from Induced Pluripotent Stem Cells. ACS Appl. Mater. Inter. 8 (34), 21923-21932. doi:10.1021/acsami. $5 \mathrm{~b} 11671$

Chang, C. W., Dalgliesh, A. J., López, J. E., and Griffiths, L. G. (2016). Cardiac Extracellular Matrix Proteomics: Challenges, Techniques, and Clinical Implications. Prot. Clin. Appl. 10 (1), 39-50. doi:10.1002/prca.201500030

Cheng, Y.-W., Shiwarski, D. J., Ball, R. L., Whitehead, K. A., and Feinberg, A. W. (2020). Engineering Aligned Skeletal Muscle Tissue Using Decellularized PlantDerived Scaffolds. ACS Biomater. Sci. Eng. 6 (5), 3046-3054. doi:10.1021/ acsbiomaterials.0c00058

Chia, H. N., and Wu, B. M. (2015). Recent Advances in 3D Printing of Biomaterials. J. Biol. Eng. 9 (1), 4. doi:10.1186/s13036-015-0001-4

Chiang, C. E., Fang, Y. Q., Ho, C. T., Assunção, M., Lin, S. J., Wang, Y. C., et al. (2021). Bioactive Decellularized Extracellular Matrix Derived from 3D Stem Cell Spheroids under Macromolecular Crowding Serves as a Scaffold for Tissue Engineering. Adv. Healthc. Mater. 10 (11), 2100024. doi:10.1002/adhm. 202100024

Choi, Y.-J., Jun, Y.-J., Kim, D. Y., Yi, H.-G., Chae, S.-H., Kang, J., et al. (2019). A 3D Cell Printed Muscle Construct with Tissue-Derived Bioink for the Treatment of Volumetric Muscle Loss. Biomaterials 206, 160-169. doi:10.1016/j.biomaterials. 2019.03.036

Choi, Y.-J., Kim, T. G., Jeong, J., Yi, H.-G., Park, J. W., Hwang, W., et al. (2016). 3D Cell Printing of Functional Skeletal Muscle Constructs Using Skeletal MuscleDerived Bioink. Adv. Healthc. Mater. 5 (20), 2636-2645. doi:10.1002/adhm. 201600483 of Dental and Craniofacial Research T90DE030859); and the Achievement Rewards for College Scientists (ARCS) Foundation.

Choi, Y.-J., Park, S. J., Yi, H.-G., Lee, H., Kim, D. S., and Cho, D.-W. (2018) Muscle-derived Extracellular Matrix on Sinusoidal Wavy Surfaces Synergistically Promotes Myogenic Differentiation and Maturation. J. Mater. Chem. B 6 (35), 5530-5539. doi:10.1039/c8tb01475b

Corona, B. T., Wu, X., Ward, C. L., McDaniel, J. S., Rathbone, C. R., and Walters, T. J. (2013). The Promotion of a Functional Fibrosis in Skeletal Muscle with Volumetric Muscle Loss Injury Following the Transplantation of Muscle-ECM. Biomaterials 34 (13), 3324-3335. doi:10.1016/j.biomaterials.2013.01.061

Crapo, P. M., Gilbert, T. W., and Badylak, S. F. (2011). An Overview of Tissue and Whole Organ Decellularization Processes. Biomaterials 32 (12), 3233-3243. doi:10.1016/j.biomaterials.2011.01.057

Csapo, R., Gumpenberger, M., and Wessner, B. (2020). Skeletal Muscle Extracellular Matrix - what Do We Know about its Composition, Regulation, and Physiological Roles? A Narrative Review. Front. Physiol. 11 (253), 253. doi:10.3389/fphys.2020.00253

Das, S., Kim, S.-W., Choi, Y.-J., Lee, S., Lee, S.-H., Kong, J.-S., et al. (2019). Decellularized Extracellular Matrix Bioinks and the External Stimuli to Enhance Cardiac Tissue Development In Vitro. Acta Biomater. 95, 188-200. doi:10.1016/j.actbio.2019.04.026

Dzobo, K., Motaung, K. S. C. M., and Adesida, A. (2019). Recent Trends in Decellularized Extracellular Matrix Bioinks for 3D Printing: An Updated Review. Ijms 20 (18), 4628. doi:10.3390/ijms20184628

Fishman, J. M., Ansari, T., Sibbons, P., De Coppi, P., and Birchall, M. A. (2012). Decellularized Rabbit Cricoarytenoid Dorsalis Muscle for Laryngeal Regeneration. Ann. Otol. Rhinol. Laryngol. 121 (2), 129-138. doi:10.1177/ 000348941212100210

Fishman, J. M., Lowdell, M. W., Urbani, L., Ansari, T., Burns, A. J., Turmaine, M., et al. (2013). Immunomodulatory Effect of a Decellularized Skeletal Muscle Scaffold in a Discordant Xenotransplantation Model. Proc. Natl. Acad. Sci. 110 (35), 14360-14365. doi:10.1073/pnas.1213228110

Fong, A. H., Romero-López, M., Heylman, C. M., Keating, M., Tran, D., Sobrino, A., et al. (2016). Three-Dimensional Adult Cardiac Extracellular Matrix Promotes Maturation of Human Induced Pluripotent Stem Cell-Derived Cardiomyocytes. Tissue Eng. A 22 (15-16), 1016-1025. doi:10.1089/ten.tea. 2016.0027

Gershlak, J. R., Hernandez, S., Fontana, G., Perreault, L. R., Hansen, K. J., Larson, S. A., et al. (2017). Crossing Kingdoms: Using Decellularized Plants as Perfusable Tissue Engineering Scaffolds. Biomaterials 125, 13-22. doi:10.1016/j. biomaterials.2017.02.011

Gilbert, T. W., Freund, J. M., and Badylak, S. F. (2009). Quantification of DNA in Biologic Scaffold Materials. J. Surg. Res. 152 (1), 135-139. doi:10.1016/j.jss.2008. 02.013

Gillies, A. R., Smith, L. R., Lieber, R. L., and Varghese, S. (2011). Method for Decellularizing Skeletal Muscle without Detergents or Proteolytic Enzymes. Tissue Eng. Part C: Methods 17 (4), 383-389. doi:10.1089/ten.tec.2010.0438

Gilpin, A., and Yang, Y. (2017). Decellularization Strategies for Regenerative Medicine: From Processing Techniques to Applications. Biomed. Res. Int. 2017, 1-13. doi:10.1155/2017/9831534

Grisales, P. A., Aziz, J. M., Muir, S. M., Marino, D. I., La Pointe, C., Asthana, A., et al. (2021). "How the Transplant Landscape Is Changing in the Regenerative Medicine Era," in Organ Repair and Regeneration. Editors G. Orlando and S. Keshavjee (Academic Press), 273-284. doi:10.1016/b978-0-12-819451-5.00009-3

Harris, A. F., Lacombe, J., and Zenhausern, F. (2021). The Emerging Role of Decellularized Plant-Based Scaffolds as a New Biomaterial. Ijms 22 (22), 12347. doi:10.3390/ijms222212347

Herrera, J., Henke, C. A., and Bitterman, P. B. (2018). Extracellular Matrix as a Driver of Progressive Fibrosis. J. Clin. Invest. 128 (1), 45-53. doi:10.1172/ jci93557

Hochman-Mendez, C., Pereira De Campos, D. B., Pinto, R. S., Mendes, B. J. d. S., Rocha, G. M., Monnerat, G., et al. (2020). Tissue-engineered Human Embryonic Stem Cell-Containing Cardiac Patches: Evaluating Recellularization of Decellularized Matrix. J. Tissue Eng. 11, 204173142092148. doi:10.1177/2041731420921482 
Jakus, A. E., Geisendorfer, N. R., Lewis, P. L., and Shah, R. N. (2018). 3D-printing Porosity: A New Approach to Creating Elevated Porosity Materials and Structures. Acta Biomater. 72, 94-109. doi:10.1016/j.actbio.2018.03.039

Jana, S., Levengood, S. K. L., and Zhang, M. (2016). Anisotropic Materials for Skeletal-Muscle-Tissue Engineering. Adv. Mater. 28 (48), 10588-10612. doi:10. 1002/adma.201600240

Jang, J., Park, H.-J., Kim, S.-W., Kim, H., Park, J. Y., Na, S. J., et al. (2017). 3D Printed Complex Tissue Construct Using Stem Cell-Laden Decellularized Extracellular Matrix Bioinks for Cardiac Repair. Biomaterials 112, 264-274. doi:10.1016/j.biomaterials.2016.10.026

Jiang, Y., Sun, S.-J., Zhen, Z., Wei, R., Zhang, N., Liao, S.-Y., et al. (2021). Myocardial Repair of Bioengineered Cardiac Patches with Decellularized Placental Scaffold and Human-Induced Pluripotent Stem Cells in a Rat Model of Myocardial Infarction. Stem Cel. Res. Ther. 12 (1), 13. doi:10. 1186/s13287-020-02066-y

Jin, Y., Jeon, E. J., Jeong, S., Min, S., Choi, Y. S., Kim, S. H., et al. (2021a). Reconstruction of Muscle Fascicle-Like Tissues by Anisotropic 3D Patterning. Adv. Funct. Mater. 31 (25), 2006227. doi:10.1002/adfm. 202006227

Jin, Y., Shahriari, D., Jeon, E. J., Park, S., Choi, Y. S., Back, J., et al. (2021b). Functional Skeletal Muscle Regeneration with Thermally Drawn Porous Fibers and Reprogrammed Muscle Progenitors for Volumetric Muscle Injury. $A d v$. Mater. 33 (14), 2007946. doi:10.1002/adma.202007946

Johnson, T. D., Dequach, J. A., Gaetani, R., Ungerleider, J., Elhag, D., Nigam, V., et al. (2014). Human versus Porcine Tissue Sourcing for an Injectable Myocardial Matrix Hydrogel. Biomater. Sci. 2 (5), 735-744. doi:10.1039/ c3bm60283d

Johnson, T. D., Hill, R. C., Dzieciatkowska, M., Nigam, V., Behfar, A., Christman, K. L., et al. (2016). Quantification of Decellularized Human Myocardial Matrix: A Comparison of Six Patients. Prot. Clin. Appl. 10 (1), 75-83. doi:10.1002/prca. 201500048

Jones, J. D., Rebello, A. S., and Gaudette, G. R. (2021). Decellularized Spinach: An Edible Scaffold for Laboratory-Grown Meat. Food Biosci. 41, 100986. doi:10. 1016/j.fbio.2021.100986

Kasukonis, B., Kim, J., Brown, L., Jones, J., Ahmadi, S., Washington, T., et al. (2016a). Codelivery of Infusion Decellularized Skeletal Muscle with Minced Muscle Autografts Improved Recovery from Volumetric Muscle Loss Injury in a Rat Model. Tissue Eng. Part A 22 (19-20), 1151-1163. doi:10.1089/ten.tea. 2016.0134

Kasukonis, B. M., Kim, J. T., Washington, T. A., and Wolchok, J. C. (2016b). Development of an Infusion Bioreactor for the Accelerated Preparation of Decellularized Skeletal Muscle Scaffolds. Biotechnol. Prog. 32 (3), 745-755. doi:10.1002/btpr.2257

Kc, P., Hong, Y., and Zhang, G. (2019). Cardiac Tissue-Derived Extracellular Matrix Scaffolds for Myocardial Repair: Advantages and Challenges. Regenerative Biomater. 6 (4), 185-199. doi:10.1093/rb/rbz017

Keane, T. J., Londono, R., Turner, N. J., and Badylak, S. F. (2012). Consequences of Ineffective Decellularization of Biologic Scaffolds on the Host Response. Biomaterials 33 (6), 1771-1781. doi:10.1016/j.biomaterials.2011.10.054

Kim, W., Lee, H., Lee, J., Atala, A., Yoo, J. J., Lee, S. J., et al. (2020). Efficient Myotube Formation in 3D Bioprinted Tissue Construct by Biochemical and Topographical Cues. Biomaterials 230, 119632. doi:10.1016/j.biomaterials. 2019.119632

Lacraz, G., Rouleau, A.-J., Couture, V., Söllrald, T., Drouin, G., Veillette, N., et al. (2015). Increased Stiffness in Aged Skeletal Muscle Impairs Muscle Progenitor Cell Proliferative Activity. PLOS ONE 10 (8), e0136217. doi:10.1371/journal. pone. 0136217

Lee, H., Ju, Y. M., Kim, I., Elsangeedy, E., Lee, J. H., Yoo, J. J., et al. (2020). A Novel Decellularized Skeletal Muscle-Derived ECM Scaffolding System for In Situ Muscle Regeneration. Methods 171, 77-85. doi:10.1016/j.ymeth.2019. 06.027

Lee, H., Kim, W., Lee, J., Park, K. S., Yoo, J. J., Atala, A., et al. (2021). Self-aligned Myofibers in 3D Bioprinted Extracellular Matrix-Based Construct Accelerate Skeletal Muscle Function Restoration. Appl. Phys. Rev. 8 (2), 021405. doi:10. $1063 / 5.0039639$

Lee, P.-F., Chau, E., Cabello, R., Yeh, A. T., Sampaio, L. C., Gobin, A. S., et al. (2017). Inverted Orientation Improves Decellularization of Whole Porcine Hearts. Acta Biomater. 49, 181-191. doi:10.1016/j.actbio.2016.11.047
Leonard, A., Bertero, A., Powers, J. D., Beussman, K. M., Bhandari, S., Regnier, M., et al. (2018). Afterload Promotes Maturation of Human Induced Pluripotent Stem Cell Derived Cardiomyocytes in Engineered Heart Tissues. J. Mol. Cell Cardiol. 118, 147-158. doi:10.1016/j.yjmcc.2018.03.016

Lichtenberg, D., Ahyayauch, H., and Goñi, F. M. (2013). The Mechanism of Detergent Solubilization of Lipid Bilayers. Biophysical J. 105 (2), 289-299. doi:10.1016/j.bpj.2013.06.007

Lindsey, M. L., Jung, M., Hall, M. E., and Deleon-Pennell, K. Y. (2018) Proteomic Analysis of the Cardiac Extracellular Matrix: Clinical Research Applications. Expert Rev. Proteomics 15 (2), 105-112. doi:10.1080/14789450. 2018.1421947

Lu, T.-Y., Lin, B., Kim, J., Sullivan, M., Tobita, K., Salama, G., et al. (2013). Repopulation of Decellularized Mouse Heart with Human Induced Pluripotent Stem Cell-Derived Cardiovascular Progenitor Cells. Nat. Commun. 4 (1), 1. doi: $10.1038 /$ ncomms3307

Merna, N., Robertson, C., La, A., and George, S. C. (2013). Optical Imaging Predicts Mechanical Properties during Decellularization of Cardiac Tissue. Tissue Eng. Part C: Methods 19 (10), 802-809. doi:10.1089/ten.tec.2012.0720

Merritt, E. K., Hammers, D. W., Tierney, M., Suggs, L. J., Walters, T. J., and Farrar, R. P. (2010). Functional Assessment of Skeletal Muscle Regeneration Utilizing Homologous Extracellular Matrix as Scaffolding. Tissue Eng. Part. A. 16 (4), 1395-1405. doi:10.1089/ten.TEA.2009.0226

Mesquita, F. C. P., Morrissey, J., Lee, P.-F., Monnerat, G., Xi, Y., Andersson, H., et al. (2021). Cues from Human Atrial Extracellular Matrix Enrich the Atrial Differentiation of Human Induced Pluripotent Stem Cell-Derived Cardiomyocytes. Biomater. Sci. 9 (10), 3737-3749. doi:10.1039/d0bm01686a

Methe, K., Bäckdahl, H., Johansson, B. R., Nayakawde, N., Dellgren, G., and Sumitran-Holgersson, S. (2014). An Alternative Approach to Decellularize Whole Porcine Heart. BioResearch Open Access 3 (6), 327-338. doi:10.1089/ biores.2014.0046

Miersch, C., Stange, K., and Röntgen, M. (2018). Effects of Trypsinization and of a Combined Trypsin, Collagenase, and DNase Digestion on Liberation and In Vitro Function of Satellite Cells Isolated from Juvenile Porcine Muscles. In Vitro Cell.Dev.Biol.-Animal 54 (6), 406-412. doi:10.1007/s11626-018-0263-5

Miranda, C. M. F. C., Leonel, L. C. P. C., Cañada, R. R., Maria, D. A., Miglino, M. A., Del Sol, M., et al. (2021). Effects of Chemical and Physical Methods on Decellularization of Murine Skeletal Muscles. Acad. Bras. Ciênc. 93 (2). doi:10.1590/0001-3765202120190942

Mousavi, A., Mashayekhan, S., Baheiraei, N., and Pourjavadi, A. (2021). Biohybrid Oxidized Alginate/myocardial Extracellular Matrix Injectable Hydrogels with Improved Electromechanical Properties for Cardiac Tissue Engineering. Int. J. Biol. Macromolecules 180, 692-708. doi:10.1016/j.ijbiomac.2021.03.097

Naik, A., Griffin, M., Szarko, M., and Butler, P. E. (2020). Optimizing the Decellularization Process of an Upper Limb Skeletal Muscle; Implications for Muscle Tissue Engineering. Artif. Organs 44 (2), 178-183. doi:10.1111/ aor. 13575

Nakamura, T., Shirouzu, T., Nakata, K., Yoshimura, N., and Ushigome, H. (2019). The Role of Major Histocompatibility Complex in Organ TransplantationDonor Specific Anti-major Histocompatibility Complex Antibodies Analysis Goes to the Next Stage -. Ijms 20 (18), 4544. doi:10.3390/ijms20184544

Nakayama, K. H., Alcazar, C., Yang, G., Quarta, M., Paine, P., Doan, L., et al. (2018). Rehabilitative Exercise and Spatially Patterned Nanofibrillar Scaffolds Enhance Vascularization and Innervation Following Volumetric Muscle Loss. Npj Regen. Med. 3 (1), 1. doi:10.1038/s41536-018-0054-3

Nakayama, K. H., Joshi, P. A., Lai, E. S., Gujar, P., Joubert, L.-M., Chen, B., et al. (2015). Bilayered Vascular Graft Derived from Human Induced Pluripotent Stem Cells with Biomimetic Structure and Function. Regenerative Med. 10 (6), 745-755. doi:10.2217/rme.15.45

Nakayama, K. H., Quarta, M., Paine, P., Alcazar, C., Karakikes, I., Garcia, V., et al. (2019). Treatment of Volumetric Muscle Loss in Mice Using Nanofibrillar Scaffolds Enhances Vascular Organization and Integration. Commun. Biol. 2 (1), 170. doi:10.1038/s42003-019-0416-4

Nakayama, K. H., Surya, V. N., Gole, M., Walker, T. W., Yang, W., Lai, E. S., et al. (2016). Nanoscale Patterning of Extracellular Matrix Alters Endothelial Function under Shear Stress. Nano Lett. 16 (1), 410-419. doi:10.1021/acs. nanolett.5b04028

Nicolas, J., Magli, S., Rabbachin, L., Sampaolesi, S., Nicotra, F., and Russo, L. (2020). 3D Extracellular Matrix Mimics: Fundamental Concepts and Role of 
Materials Chemistry to Influence Stem Cell Fate. Biomacromolecules 21 (6), 1968-1994. doi:10.1021/acs.biomac.0c00045

Ostrovidov, S., Hosseini, V., Ahadian, S., Fujie, T., Parthiban, S. P., Ramalingam, M., et al. (2014). Skeletal Muscle Tissue Engineering: Methods to Form Skeletal Myotubes and Their Applications. Tissue Eng. B: Rev. 20 (5), 403-436. doi:10. 1089/ten.teb.2013.0534

Ott, H. C., Matthiesen, T. S., Goh, S.-K., Black, L. D., Kren, S. M., Netoff, T. I., et al. (2008). Perfusion-decellularized Matrix: Using Nature's Platform to Engineer a Bioartificial Heart. Nat. Med. 14 (2), 213-221. doi:10.1038/nm1684

Ozlu, B., Ergin, M., Budak, S., Tunali, S., Yildirim, N., and Erisken, C. (2019). A Bioartificial Rat Heart Tissue: Perfusion Decellularization and Characterization. Int. J. Artif. Organs 42 (12), 757-764. doi:10.1177/0391398819863434

Patel, K. H., Dunn, A. J., Talovic, M., Haas, G. J., Marcinczyk, M., Elmashhady, H., et al. (2019). Aligned Nanofibers of Decellularized Muscle ECM Support Myogenic Activity in Primary Satellite Cells In Vitro. Biomed. Mater. 14 (3), 035010. doi:10.1088/1748-605X/ab0b06

Patel, K. H., Talovic, M., Dunn, A. J., Patel, A., Vendrell, S., Schwartz, M., et al. (2020). Aligned Nanofibers of Decellularized Muscle Extracellular Matrix for Volumetric Muscle Loss. J. Biomed. Mater. Res. 108 (6), 2528-2537. doi:10. 1002/jbm.b.34584

Perea-Gil, I., Gálvez-Montón, C., Prat-Vidal, C., Jorba, I., Segú-Vergés, C., Roura, S., et al. (2018). Head-to-head Comparison of Two Engineered Cardiac Grafts for Myocardial Repair: From Scaffold Characterization to Pre-clinical Testing. Sci. Rep. 8 (1), 1. doi:10.1038/s41598-018-25115-2

Piccoli, M., Trevisan, C., Maghin, E., Franzin, C., and Pozzobon, M. (2017). Mouse Skeletal Muscle Decellularization. New York: Springer, 87-93. doi:10.1007/ 7651_2017_28

Porzionato, A., Sfriso, M., Pontini, A., Macchi, V., Petrelli, L., Pavan, P., et al. (2015). Decellularized Human Skeletal Muscle as Biologic Scaffold for Reconstructive Surgery. Ijms 16 (12), 14808-14831. doi:10.3390/ ijms 160714808

Puri, S., Coulson-Thomas, Y. M., Gesteira, T. F., and Coulson-Thomas, V. J. (2020). Distribution and Function of Glycosaminoglycans and Proteoglycans in the Development, Homeostasis and Pathology of the Ocular Surface. Front. Cel. Dev. Biol. 8, 731. doi:10.3389/fcell.2020.00731

Quake, S. (2011). DNA Mismatch Reveals Organ Rejection [Online]. Nature doi:10.1038/news.2011.189

Raffa, P., Scattolini, V., Gerli, M. F. M., Perin, S., Cui, M., De Coppi, P., et al. (2020). Decellularized Skeletal Muscles Display Neurotrophic Effects in ThreeDimensional Organotypic Cultures. STEM CELLS Translational Med. 9 (10), 1233-1243. doi:10.1002/sctm.20-0090

Rando, T. A., and Ambrosio, F. (2018). Regenerative Rehabilitation: Applied Biophysics Meets Stem Cell Therapeutics. Cell Stem Cell 22 (3), 306-309. doi:10.1016/j.stem.2018.02.003

Reyna, W. E., Pichika, R., Ludvig, D., and Perreault, E. J. (2020). Efficiency of Skeletal Muscle Decellularization Methods and Their Effects on the Extracellular Matrix. J. Biomech. 110, 109961. doi:10.1016/j.jbiomech.2020. 109961

Robbins, E. R., Pins, G. D., Laflamme, M. A., and Gaudette, G. R. (2020). Creation of a Contractile Biomaterial from a Decellularized Spinach Leaf without ECM Protein Coating: An In Vitro Study. J. Biomed. Mater. Res. 108 (10), 2123-2132. doi:10.1002/jbm.a.36971

Robertson, M. J., Dries-Devlin, J. L., Kren, S. M., Burchfield, J. S., and Taylor, D. A. (2014). Optimizing Recellularization of Whole Decellularized Heart Extracellular Matrix. PLoS ONE 9 (2), e90406. doi:10.1371/journal.pone. 0090406

Sarig, U., Sarig, H., de-Berardinis, E., Chaw, S.-Y., Nguyen, E. B. V., Ramanujam, V. S., et al. (2016). Natural Myocardial ECM Patch Drives Cardiac Progenitor Based Restoration Even after Scarring. Acta Biomater. 44, 209-220. doi:10. 1016/j.actbio.2016.08.031

Schwan, J., Kwaczala, A. T., Ryan, T. J., Bartulos, O., Ren, Y., Sewanan, L. R., et al. (2016). Anisotropic Engineered Heart Tissue Made from Laser-Cut Decellularized Myocardium. Sci. Rep. 6 (1), 32068. doi:10.1038/srep32068

Shah, M., Kc, P., Copeland, K. M., Liao, J., and Zhang, G. (2018). A Thin Layer of Decellularized Porcine Myocardium for Cell Delivery. Sci. Rep. 8 (1), 1. doi:10. 1038/s41598-018-33946-2

Shapira-Schweitzer, K., and Seliktar, D. (2007). Matrix Stiffness Affects Spontaneous Contraction of Cardiomyocytes Cultured within a PEGylated
Fibrinogen Biomaterial. Acta Biomater. 3 (1), 33-41. doi:10.1016/j.actbio.2006. 09.003

Shapiro, L., Elsangeedy, E., Lee, H., Atala, A., Yoo, J. J., Lee, S. J., et al. (2019). In Vitro evaluation of Functionalized Decellularized Muscle Scaffold for In Situ Skeletal Muscle Regeneration. Biomed. Mater. 14 (4), 045015. doi:10.1088/ $1748-605 x / a b 229 d$

Sharma, M., Kumar, R., Sharma, S., Thomas, B., Kapatia, G., Singh, G., et al. (2019). Sustained Exposure to Trypsin Causes Cells to Transition into a State of Reversible Stemness that Is Amenable to Transdifferentiation. Cold Spring Harbor, NY: Cold Spring Harbor Laboratory.

Silva, A. C., Rodrigues, S. C., Caldeira, J., Nunes, A. M., Sampaio-Pinto, V., Resende, T. P., et al. (2016). Three-dimensional Scaffolds of Fetal Decellularized Hearts Exhibit Enhanced Potential to Support Cardiac Cells in Comparison to the Adult. Biomaterials 104, 52-64. doi:10.1016/j. biomaterials.2016.06.062

Singelyn, J. M., Sundaramurthy, P., Johnson, T. D., Schup-Magoffin, P. J., Hu, D. P., Faulk, D. M., et al. (2012). Catheter-deliverable Hydrogel Derived from Decellularized Ventricular Extracellular Matrix Increases Endogenous Cardiomyocytes and Preserves Cardiac Function post-myocardial Infarction. J. Am. Coll. Cardiol. 59 (8), 751-763. doi:10.1016/j.jacc.2011.10.888

Skoog, S. A., Kumar, G., Narayan, R. J., and Goering, P. L. (2018). Biological Responses to Immobilized Microscale and Nanoscale Surface Topographies. Pharmacol. Ther. 182, 33-55. doi:10.1016/j.pharmthera. 2017.07.009

Smoak, M. M., Han, A., Watson, E., Kishan, A., Grande-Allen, K. J., CosgriffHernandez, E., et al. (2019). Fabrication and Characterization of Electrospun Decellularized Muscle-Derived Scaffolds. Tissue Eng. Part C: Methods 25 (5), 276-287. doi:10.1089/ten.tec.2018.0339

Soto-Gutierrez, A., Zhang, L., Medberry, C., Fukumitsu, K., Faulk, D., Jiang, H., et al. (2011). A Whole-Organ Regenerative Medicine Approach for Liver Replacement. Tissue Eng. Part C: Methods 17 (6), 677-686. doi:10.1089/ten. tec.2010.0698

Spector, I., Shochet, N. R., Kashman, Y., and Groweiss, A. (1983). Latrunculins: Novel Marine Toxins that Disrupt Microfilament Organization in Cultured Cells. Science 219 (4584), 493-495. doi:10. $1126 /$ science.6681676

Suh, T. C., Amanah, A. Y., and Gluck, J. M. (2020). Electrospun Scaffolds and Induced Pluripotent Stem Cell-Derived Cardiomyocytes for Cardiac Tissue Engineering Applications. Bioengineering 7 (3), 105. doi:10.3390/ bioengineering 7030105

Talovic, M., Patel, K., Schwartz, M., Madsen, J., and Garg, K. (2019). Decellularized Extracellular Matrix Gelloids Support Mesenchymal Stem Cell Growth and Function In Vitro. J. Tissue Eng. Regen. Med. 13 (10), 1830-1842. doi:10.1002/ term. 2933

Tsui, J. H., Leonard, A., Camp, N. D., Long, J. T., Nawas, Z. Y., Chavanachat, R., et al. (2021). Tunable Electroconductive Decellularized Extracellular Matrix Hydrogels for Engineering Human Cardiac Microphysiological Systems. Biomaterials 272, 120764. doi:10.1016/j.biomaterials.2021. 120764

Ungerleider, J. L., Johnson, T. D., Rao, N., and Christman, K. L. (2015). Fabrication and Characterization of Injectable Hydrogels Derived from Decellularized Skeletal and Cardiac Muscle. Methods 84, 53-59. doi:10.1016/j.ymeth.2015. 03.024

Urciuolo, A., Urbani, L., Perin, S., Maghsoudlou, P., Scottoni, F., Gjinovci, A., et al. (2018). Decellularised Skeletal Muscles Allow Functional Muscle Regeneration by Promoting Host Cell Migration. Sci. Rep. 8 (1), 8398. doi:10.1038/s41598018-26371-y

Wainwright, J. M., Czajka, C. A., Patel, U. B., Freytes, D. O., Tobita, K., Gilbert, T. W., et al. (2010). Preparation of Cardiac Extracellular Matrix from an Intact Porcine Heart. Tissue Eng. Part C: Methods 16 (3), 525-532. doi:10.1089/ten.tec. 2009.0392

Walimbe, T., and Panitch, A. (2020). Proteoglycans in Biomedicine: Resurgence of an Underexploited Class of ECM Molecules. Front. Pharmacol. 10 (1661), 1661. doi:10.3389/fphar.2019.01661

Wang, Q., Yang, H., Bai, A., Jiang, W., Li, X., Wang, X., et al. (2016). Functional Engineered Human Cardiac Patches Prepared from Nature's Platform Improve Heart Function after Acute Myocardial Infarction. Biomaterials 105, 52-65. doi:10.1016/j.biomaterials.2016.07.035 
Wang, X., Pierre, V., Liu, C., Senapati, S., Park, P. S.-H., and Senyo, S. E. (2021). Exogenous Extracellular Matrix Proteins Decrease Cardiac Fibroblast Activation in Stiffening Microenvironment through CAPG. J. Mol. Cell Cardiol. 159, 105-119. doi:10.1016/j.yjmcc.2021.06.001

Wang, X., Senapati, S., Akinbote, A., Gnanasambandam, B., Park, P. S.-H., and Senyo, S. E. (2020). Microenvironment Stiffness Requires Decellularized Cardiac Extracellular Matrix to Promote Heart Regeneration in the Neonatal Mouse Heart. Acta Biomater. 113, 380-392. doi:10.1016/j.actbio.2020.06.032

Wang, Z., Long, D. W., Huang, Y., Chen, W. C. W., Kim, K., and Wang, Y. (2019). Decellularized Neonatal Cardiac Extracellular Matrix Prevents Widespread Ventricular Remodeling in Adult Mammals after Myocardial Infarction. Acta Biomater. 87, 140-151. doi:10.1016/j.actbio.2019.01.062

Wilgus, T. A. (2012). Growth Factor-Extracellular Matrix Interactions Regulate Wound Repair. Adv. Wound Care 1 (6), 249-254. doi:10.1089/wound.2011. 0344

Williams, C., Quinn, K. P., Georgakoudi, I., and Black, L. D. (2014). Young Developmental Age Cardiac Extracellular Matrix Promotes the Expansion of Neonatal Cardiomyocytes In Vitro. Acta Biomater. 10 (1), 194-204. doi:10. 1016/j.actbio.2013.08.037

Wolf, M. T., Daly, K. A., Reing, J. E., and Badylak, S. F. (2012). Biologic Scaffold Composed of Skeletal Muscle Extracellular Matrix. Biomaterials 33 (10), 2916-2925. doi:10.1016/j.biomaterials.2011.12.055

World Health Organization, WHO (2021a). Cardiovascular Diseases (CVDs) [Online]. Available at: https://www.who.int/news-room/fact-sheets/detail/ cardiovascular-diseases-(cvds (Accessed December 3, 2021).

World Health Organization, WHO (2021b). Musculoskeletal Conditions [Online]. Available at: https://www.who.int/news-room/fact-sheets/detail/musculoskeletalconditions (Accessed December 3, 2021).

Xu, X., Sharma, P., Shu, S., Lin, T.-S., Ciais, P., Tubiello, F. N., et al. (2021). Global Greenhouse Gas Emissions from Animal-Based Foods Are Twice Those of Plant-Based Foods. Nat. Food 2 (9), 724-732. doi:10.1038/s43016021-00358-x
Yelin, E. H., Cisternas, M., and Watkins-Castillo, S. I. (2021). The Burden of Muskuloskeletal Diseases in the United States [Online]. Available at: https://www. boneandjointburden.org/fourth-edition/if1/direct-costs (Accessed December 3, 2021).

Yingchoncharoen, T., Agarwal, S., Popović, Z. B., and Marwick, T. H. (2013). Normal Ranges of Left Ventricular Strain: a Meta-Analysis. J. Am. Soc Echocardiography 26 (2), 185-191. doi:10.1016/j.echo.2012.10.008

Zhang, J., Hu, Z. Q., Turner, N. J., Teng, S. F., Cheng, W. Y., Zhou, H. Y., et al. (2016). Perfusion-decellularized Skeletal Muscle as a Three-Dimensional Scaffold with a Vascular Network Template. Biomaterials 89, 114-126. doi:10.1016/j.biomaterials.2016.02.040

Zhang, J., Zhu, W., Radisic, M., and Vunjak-Novakovic, G. (2018). Can We Engineer a Human Cardiac Patch for Therapy? Circ. Res. 123 (2), 244-265. doi:10.1161/circresaha.118.311213

Conflict of Interest: The authors declare that the research was conducted in the absence of any commercial or financial relationships that could be construed as a potential conflict of interest.

Publisher's Note: All claims expressed in this article are solely those of the authors and do not necessarily represent those of their affiliated organizations, or those of the publisher, the editors and the reviewers. Any product that may be evaluated in this article, or claim that may be made by its manufacturer, is not guaranteed or endorsed by the publisher.

Copyright (c) 2022 Tan, Helms and Nakayama. This is an open-access article distributed under the terms of the Creative Commons Attribution License (CC $B Y)$. The use, distribution or reproduction in other forums is permitted, provided the original author(s) and the copyright owner(s) are credited and that the original publication in this journal is cited, in accordance with accepted academic practice. No use, distribution or reproduction is permitted which does not comply with these terms. 